\title{
Speed-up of Computing Time for Numerical Analysis of Particle Charging Process by using Discrete Element Method
}

\author{
Hiroshi Mio ${ }^{1,2 *}$, Masatoshi Akashi ${ }^{3}$, Atsuko Shimosaka ${ }^{3}$, \\ Yoshiyuki Shirakawa $^{3}$, Jusuke Hidaka ${ }^{3}$ and Shinroku Matsuzaki ${ }^{4}$ \\ 1) Kyoto Fine Particle Technology, Keihanna Interaction Plaza Inc. \\ 1-7 Hikaridai, Seika-cho, Soraku-gun, Kyoto 619-0237, Japan
}

2) Research Center for Advanced Science and Technology, Doshisha University

1-3 Tatara-miyakodani, Kyotanabe, Kyoto 610-0321, Japan

3) Department of Chemical Engineering and Materials Science, Doshisha University

1-3 Tatara-miyakodani, Kyotanabe, Kyoto 610-0321, Japan

4) Environment and Process Technology Center, Nippon Steel Corporation

20-1 Shintomi, Futtsu, Chiba 293-8511, Japan

* Corresponding author; Hiroshi Mio, Dr.

Kyoto Fine Particle Technology, Keihanna Interaction Plaza Inc.

1-7 Hikaridai, Seika-cho, Soraku-gun, Kyoto 619-0237, Japan

Tel: +81-(0)774-98-2210, FAX: +81-(0)774-98-2214

E-mail: mio@kcoe.jp 


\section{Abstract}

The objective of this paper is to improve the computing time for numerical analysis of particle charging process by using Discrete Element Method. The rule for ignoring the calculations of contact forces and updating trajectories of unmoved particles were discussed. When the relative displacement of a particle within certain calculation steps became less than $0.1 \%$ of particle radius, this particle was determined to be unmoved and the calculations of this particle were ignored. The computing time was improved significantly when this new method was used, and its calculation speed was more than two times faster than that of original. It was found that this speed-up method is more useful for the cases that the particle becomes unmoved in short time or the height of charged bed is large. The simulation of charging process in an industrial-scale surge hopper was studied by using new method, the calculation speed became 2.88 times faster than that of original, and the quite similar particle size segregation between original and new methods was given. This new method for speed-up of the charging process in DEM is very useful, and the charging processes of the industrial scale storages can be simulated by using this method. 


\section{Keywords}

Granular materials, Packed bed, Powder technology, Simulation, Discrete Element

Method, Speed-up 


\section{Introduction}

Discrete Element Method (DEM) (Cundall and Strack, 1979) is one of the most famous and reliable simulation methods for the numerical analysis of solid particle behavior, and many researches on the particulate processes; such as hopper (Cleary and Sawley, 2002; Zhu et al., 2006; Ketterhangen et al., 2008), rotating drum (Yang et al., 2003; Taberlet et al., 2006), blast furnace (Yuu et al., 2005; Zhou et al., 2005; Mio et al., 2007a), particle breakage (Moreno et al., 2003; Thornton and Liu, 2004), mixing (Bertrand et al., 2005; Arratia et al., 2006), electrophotographic system (Severens et al., 2006; Mio et al., 2006a), ball milling (Rajamani et al., 2000; Gudin et al., 2006; Mio et al., 2007b), fluidized bed (Kaneko et al., 1999; Kawaguchi et al., 2000; Kafui et al., 2002) and so on, have been modeled by using DEM. They have given many significant results and useful information, however there is still important issue on DEM work; i.e. that's the speed-up of computing time. DEM consists of an idea of determining the kinematic force to each finite-sized particle at every discrete time step, thus the calculation time increases with increasing not only the number of particles also total calculation steps. This is a serious problem for the simulation of particle charging process, especially analyses of industrial scale storages. There are usually uncounted numbers of particles in these processes, 
and they also have large particle size distribution. The calculation load becomes larger and larger with proceeding charging, because the number of contacts between particles in charged bed increases extremely. Therefore, the speed-up of DEM calculation is one of the most important issues to analyze the particle size segregation, the wall stress or the packing fraction of the charged bed in detail.

There are five possible solutions for speed-up of DEM calculation.

1) Optimizations of hardware and software (Mio et al., 2007c)

2) Program optimization (Mio et al., 2007c)

3) Improving DEM algorithm (Mio et al., 2005; 2006b; 2007d)

4) Parallel computing (Carrillo et al., 1999; Cleary and Sawley, 2002)

5) Simplifying the proper calculation process (Mio et al., 2007e)

First one is the easiest way for speed-up, however the program optimization for the proper processors or compilers is more important because the calculation speed depends on how to write a cord (Mio et al., 2007c). Improving DEM algorithm is the most important and practical. The most of calculation load in DEM calculation is usually in the particle detection process, and the authors had proposed the optimization method of the cell for particle detection (Mio et al., 2005; 2006b; 2007d). Parallel computing by using Message Passing Interface (MPI) or OpenMP is 
a very attractive method for large-scale computing, and this is definitely effective after the serial cord have been tuned up. The fifth one is the commonest method for speed-up by using the smaller spring coefficient, the mono-size particles or cutoff distance for long-range force calculation. The effects of these kinds of simplifications on the calculated results should be checked, because there are sometimes problems on the results.

The calculation speed in particle charging process will be able to be improved because the particles in the charged bed cannot move. Thus, it is not necessary to calculate contact force between unmoved particles, and the role of ignoring force calculation is very important to keep the calculation precision. In this paper, the speed-up method for particle charging process by using DEM was proposed, and the role of ignoring the calculation and its effect on the results were discussed.

\section{Simulation}

\section{Discrete Element Method}

Discrete Element Method (DEM) (Cundall and Strack, 1979) is one of the most popular and reliable simulation methods for the numerical analysis of solid particle behavior. This simulation method consists of the idea of determining the kinematic 
force to each finite-sized particle. The main calculation of DEM consists three steps; i.e. 1) particle detection, 2) calculation of forces, 3) update of trajectories, and these processes are looped until $t=t_{\max }$. The particle detection process has the heaviest calculation load in DEM (Mio et al., 2005). The speed-up of particle detection process is possible by optimizing the cell condition (Mio et al., 2007d). The contact between two particles is represented by Voigt model, which consists of the spring-dashpot and a slider for the friction in tangential component. The contact forces, $F_{\mathrm{n}}$ and $F_{\mathrm{t}}$, are calculated by following equations.

$$
\begin{aligned}
& \mathbf{F}_{\mathrm{n}, i j}=\left(K_{n} \Delta u_{n, i j}+\eta_{n} \frac{\Delta u_{n, i j}}{\Delta t}\right) \mathbf{n}_{i j} \\
& \mathbf{F}_{\mathrm{t}, i j}=\min \left\{\mu\left|\mathrm{F}_{n, i j}\right| \mathbf{t}_{i j},\left[K_{t}\left(\Delta u_{t, i j}+\Delta \phi_{i j}\right)+\eta_{t}\left(\frac{\Delta u_{t, i j}+\Delta \phi_{i j}}{\Delta t}\right)\right] \mathbf{t}_{i j}\right\}
\end{aligned}
$$

Where, $K$ and $\eta$ mean the spring and the damping coefficients. $\Delta u$ and $\Delta \phi$ are a relative translational displacement of gravitational center between two particles and a relative displacement at the contact point caused by the particle rotation. $\mu$ is the frictional coefficient. $\quad \mathbf{n}_{i j}$ and $\mathbf{t}_{i j}$ denote the unit vector from $i$-th particle to $j$-th one in normal and tangential components. The subscript $\mathrm{n}$ and $\mathrm{t}$ also denote the normal and tangential components. The translational and rotational motions of each 
particle are updated by following equations.

$$
\begin{aligned}
& \dot{\mathbf{v}}=\frac{\sum \mathbf{F}}{m}+\mathbf{g} \\
& \dot{\boldsymbol{\omega}}=\frac{\sum \mathbf{M}}{I}
\end{aligned}
$$

Where, $\mathbf{v}$ is the vector of a particle velocity, $\mathbf{F}$ is the contact force acting on a particle, $m$ and $\mathbf{g}$ mean the mass of a particle and gravitational acceleration, $\omega$ is the vector of angular velocity, $\mathbf{M}$ and $I$ denote the moment caused by the tangential force and the moment of inertia.

\section{Simulation condition}

Three cases of particle charging system were examined in this work;

(I) Charging to hopper bin

(II) Discharging from hopper to a container (three different sizes)

(III) Charging to an industrial-scale surge hopper from a conveyor

The hopper bin, which was used in the cases (I) and (II), had an outlet (diameter:

$27.0 \mathrm{~mm}$ and inclination: $70^{\circ}$ ). 32822 particles (Young's modulus: $4.5 \mathrm{GPa}$, Poisson's ratio: 0.35 and density: $1300 \mathrm{~kg} / \mathrm{m}^{3}$ ) having $1.25 \mathrm{~mm}$ (number of particles; $n=21028), 1.75 \mathrm{~mm}(n=8515), 2.50 \mathrm{~mm}(n=2628)$ or $4.50 \mathrm{~mm}(n=651)$ in diameter were calculated in cases (I) and (II). 2388 particles were charged to the 
hopper bin at every 426935 steps (case (I)). The particles in the hopper bin were discharged through the bottom outlet to the container having $44.0,62.8$ or $81.6 \mathrm{~mm}$ in width (case (II)). The container width was changed to discuss the effect of the slope length of heap on the speed-up of computing time, and the depth and height of them were $30 \mathrm{~mm}$ and $130 \mathrm{~mm}$ in all containers. $\Delta t$ was $4.0 \times 10^{-7} \mathrm{~s}$. The calculations of cases (I) and (II) were executed in a workstation; processor: PowerPC970 1.6GHz and compiler: IBM XL Fortran ver. 9.1.

538240 particles (Young's modulus: 35 GPa, Poisson's ratio: 0.25 and density: $\left.3300 \mathrm{~kg} / \mathrm{m}^{3}\right)$ having $22.5 \mathrm{~mm}(n=451050), 37.5 \mathrm{~mm}(n=60470), 60.0 \mathrm{~mm}(n=$ $22140)$ or $97.5 \mathrm{~mm}(n=4580)$ in diameter were charged in the industrial-scale surge hopper (case (III)), whose height, width or depth were 7100,3500 or 1000 $\mathrm{mm}$, respectively. The particles are charged from the conveyor, and its speed was $2.0 \mathrm{~m} / \mathrm{s} . \Delta t$ was $1.0 \times 10^{-6} \mathrm{~s}$, and Athlon $642.8 \mathrm{GHz}$ of processor and PGI compiler ver. 6.2 were used in this calculation.

\section{Speed-up method of particle charging process}

Figure 1 shows the relation between the computing time and calculation steps in the case (I). It is found easily that the calculation speed becomes slower and 
slower with charge progresses, that is caused by increasing the calculation load of contact force between particles in charged bed, which is shown in Figure 2. However, the particles in charged bed cannot move, and the resultant force of these particles is almost zero as illustrated in Figure 3, i.e. eq.(5) is given.

$$
\mathbf{F}_{i}=\sum_{k} \mathbf{F}_{k, i}+\mathbf{F}_{\mathrm{g}, i} \approx 0
$$

Where, $\mathbf{F}_{k}$ is the contact force acting on $i$ th particle, and $\mathbf{F}_{\mathrm{g}}$ is the gravitational force. Thus, it isn't necessary to calculate the contact forces (Eqs.(1) and (2)) and update particle positions (Eqs.(3) and (4)) of unmoved particles. Therefore, the computing time will be able to be improved by ignoring the calculations of these particles.

A rule for ignoring calculations of unmoved particles is very important, and this affects the speed-up and the calculation precision strongly. Figure 4 shows the relation between the vertical positions, $u_{z}$ for three particles and the calculation step. $u_{z}$ were hardly changed after they fell on the particle bed. Figure $\mathbf{5}$ shows the relative displacement of 3025th particle, $\chi_{i}$, within $\tau$ steps, and $\chi_{i}$ defined by following equation.

$$
\chi_{i}=\frac{\sum_{t=\tau_{0}+1}^{\tau_{0}+\tau} \Delta u_{i, t}}{r_{i}}
$$

It is found from Fig.5 that the relative displacement decreases with increasing 
calculation step, and this particle becomes unmoved. $\chi_{i}$ sometimes becomes large again after $\chi_{i}$ was nearly zero, because some large particles fell on the particle bed, then it starts to move again. $\chi_{i}$ for $\tau=1000$ seems to be too small for determination of stable particle. Thus, the rule for ignoring calculations of unmoved particles was made as follows.

1) When $\left|\chi_{i}\right|$ is smaller than $0.1 \%$ of particle radius, this particle determined to be the "temporary-unmoved" particle at this moment, and $\Psi_{i}=\Psi_{i}+1$.

2) If $\Psi_{i}=\Psi_{0}$, this particle determined to be the "permanently-unmoved" particle.

3) The contact force between the permanently-unmoved particle and wall is ignored.

4) The contact force between the permanently-unmoved particles is ignored. However, the force between the moving particle and the permanently-unmoved one is calculated. Thus, the position of permanently-unmoved particle must be kept in the grid cell for the particle detection.

5) The updates of position and velocity for the permanently-unmoved particle are ignored. 
$\Psi_{i}$ is the counter for the determination of ignoring for $i$ th particle, and $\Psi_{0}$ is maximum count. $\Psi_{0}$ is used for considering the situation that a particle is static temporary and then it starts to move again. If $\Psi_{0}$ is large, the particle is selected to be the temporary-unmoved many times, however it is hardly selected to be the permanently-unmoved.

\section{Results and Discussions}

Figure 6 shows the snapshots of particle charging behavior in the hopper bin (case (I)) calculated by using the new method under $\tau=100000$ and $\Psi_{0}=3$. The colors of particles designate $\Psi_{i}$; i.e. white $\left(\Psi_{i}=0\right)$, gray $\left(\Psi_{i}=1\right)$, dark gray $\left(\Psi_{i}=2\right)$ and black $\left(\Psi_{i}=3\right)$. The black particles denote "permanently-unmoved", and the force calculations and update for them are being ignored. It is observed from Fig. 6 that the particles in charged bed are determined to be temporary-unmoved or permanently-unmoved with charge progresses. Figure 7 shows the computing times of new and original calculation methods. The time of new method at $8 \mathrm{M}$ steps is $48.3 \%$ of that of original, and it is easily understood that the computing time is improved significantly. Figure $\mathbf{8}$ shows the relation between the number of contact force calculations between particles and the calculation step. The 
calculation load was reduced a lot by ignoring the calculations of unmoved particles. The packing fractions in the hopper bin are 0.640 (original) and 0.638 (new), respectively. Thus, this new calculation method can keep a precision of the result. Table 1 shows the computing times of new method under different $\tau$ or $\Psi_{i}$. The

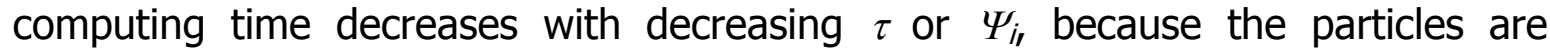
determined to be permanently-unmoved easily. It seems that $\tau$ affects calculation speed more than $\Psi_{i}$. The relative wall stresses $\left(p / p_{\text {original }}\right)$ on the hopper under the different $\tau$ were $0.976(\tau=100000), 0.982(\tau=50000), 0.932(\tau=30000)$ and $0.898(\tau=20000)$. Figure 9 shows the packing fractions, $\varphi$, under different $\tau$ and $\Psi_{0}$. When $\Psi_{i}$ decreased, $\varphi$ becomes smaller when $\tau$ was kept constant, and $\varphi$ also decreases with decreasing $\tau . \quad \varphi$ of $\tau=50000$ and $\Psi_{i}=3(\mathrm{~V})$ is closer to original packing fraction than that of $\tau=100000$ and $\Psi_{i}=1$ (IV), although the computing time for $\tau=50000$ and $\Psi_{i}=3(\mathrm{~V})$ is faster than that for $\tau=100000$ and $\Psi_{i}=1$ (IV). Therefore, $\Psi_{i}$ is more important to keep a precision of result and improve the calculation speed, and the condition of $\tau=50000$ and $\Psi_{i}=3$ works very well.

Figure $\mathbf{1 0}$ shows the snapshots of particle discharging behavior from a hopper under the conditions of $\tau=50000$ and $\Psi_{i}=3$. The particle color also designates $\Psi_{i r}$ and the particle color is changed from the particles that locate at the bottom. 
Table 2 shows the computing time for 3M steps, the angle of repose of charged bed and the packing fraction of new and original calculation methods. The calculation speed becomes about $25 \%$ faster than that of original ( $\tau=30000$ and $\Psi_{i}=3$ ), and the angle of repose and the packing fractions for new method are mostly same value of original one, even $\tau=30000$. Table 3 shows the relative computing time under the different container width ( $\tau=30000$ and $\Psi_{i}=3$ ). The relative time is increased with increasing the container width, because the length of slope of heap becomes large, leading to increasing the time to reach at the side wall, and the height of particle bed also becomes small. The reason why the speed-up of case (I) is much larger than that of case (II) is the difference of relative number of the permanently-unmoved particles during calculation. Figure $\mathbf{1 1}$ shows the relation between the percentage of the number of unmoved particles, $P_{\mathrm{u}}$ and the normalized calculation step, $t_{\mathrm{i}} / t_{\mathrm{fin}}, t_{\mathrm{fin}}$ : the number of calculation steps for finish the charging. $P_{\mathrm{u}}$ for case (I) is much larger than those of case (II), when they are compared at same $t_{\mathrm{i}} / t_{\text {fin }}$. The flow rates of these conditions were 13983 particles/s (case (I)) and 41695 particles/s (case (II)), thus the total number of calculation step in case (I) becomes large and the particles become permanently-unmoved easily when the flow rate is smaller. Therefore, this speed-up method is more useful for the cases; i.e. 
- The particles become unmoved in short time.

- The large number of calculation steps is required.

- The height of particle bed is large.

This new calculation method will be very effective for the calculation of industrial-scale storage system.

Figure 12 shows the relation between the computing time and the calculation step when 538240 particles are charged to the surge hopper. $\quad \tau=30000$ and $\Psi_{i}=3$ are used in this calculation. The computing time to finish charging (34M steps) were $1.17 \times 10^{7} \mathrm{~s}$ (original method; 3252 hours) and $4.07 \times 10^{6} \mathrm{~s}$ (new method; 1130 hours), respectively. The new method is 2.88 times faster than that of original, and the calculation time of new method is $0.222 \mathrm{~s}$ when the calculation condition is converted to the condition of 1000 particles and 1000 steps (Mio et al., 2007c). This calculation speed is quite fast whereas the large number of particles having particle size distribution was calculated. Figure $\mathbf{1 3}$ shows the snapshots of the cross section of charged particles in the surge hopper, the particle colors designate the particle size. The particle size segregation found in these figures seem to be quite similar, and Figure $\mathbf{1 4}$ shows the mapping of mass fraction for the smallest (22.5 $\mathrm{mm})$ or the largest $(97.5 \mathrm{~mm})$ particles in the surge hopper. The grid was 
installed in the surge hopper along with the slope of side wall, and the mass fraction of particles at each grid was calculated. The strong particle size segregation was seen in the surge hopper because the large particles are sliding toward left wall along with the slope of heap, and they are segregated during flowing. The mapping for both calculation methods are mostly same, and Figure $\mathbf{1 5}$ shows the distribution of the mass fraction at each grid in the surge hopper. The distributions of original and new methods seem quite similar for both in smallest and largest particles. Therefore, it is concluded that this new method for speed-up of numerical analysis of the particle charging process using DEM is very useful, and the charging processes of the industrial scale storages can be simulated by using this method.

\section{Conclusion}

In this paper, the speed-up method of the calculation of particle charging process by using DEM was proposed. The calculations of unmoved particles in the charged bed were ignored, and the unmoved particles were determined by checking the relative displacement within certain calculation steps. The followings are the summaries of this work. 
i) The calculation time was improved significantly when the new method was used, and its calculation speed was more than two times faster than that of original.

ii) $\quad \Psi_{i}$ is more important than $\tau$ to keep a precision of result and improve the calculation speed.

iii) This speed-up method is more useful for the cases that the particle becomes unmoved in short time, the large number of calculation steps is required or the height of charged bed is large.

iv) The calculation of charging process in the industrial-scale surge hopper by using new method became 2.88 times faster than that of original, and the quite similar particle size segregation between original and new ones was observed.

v) This new method for speed-up the charging process in DEM is very useful, and the charging processes of the industrial scale storages can be simulated by using this method. 


\section{Acknowledgement}

The authors are grateful to JST (Japan Science and Technology Agency) for

financial support on this project; Kyoto Prefecture Collaboration of Regional Entities for the Advancement of Technological Excellence. 


\section{References}

Arratia, P.E., Duong, N.-H., Muzzio, F.J., Godbole, P., Reynolds, S., (2006). A study of the mixing and segregation mechanisms in the Bohle Tote blender via DEM simulations. Powder Technology, 164, 50-57.

Bertrand, F., Leclaire, L.-A., Levecque, G., (2005). DEM-based models for the mixing of granular materials. Chemical Engineering Science, 60, 2517-2531.

Carrillo, A.R., West, J.E., Horner, D.A., Peters, J.F., (1999). Interactive Large-Scale Soil Modeling using Distributed High Performance Computing Environment. The International Journal of High Performance Computing Applications, 13, 33-48.

Cleary, P.W., Sawley, M.L., (2002). DEM modeling of industrial granular flows: 3D case studies and the effect of particle shape on hopper discharge. Applied Mathematical Modelling, 26, 89-111.

Cundall, P.A., Strack, O.D.L., (1979). A Discrete Numerical Model for Granular Assemblies. Geotechnique, 29, 47-65.

Gudin, D., Turczyn, R., Mio, H., Kano, J., Saito, F., (2006). Simulation of the Movement of Beads by the Discrete Element Method with Respect to the Wet Grinding Process. AIChE Journal, 52, 3421-3426.

Kafui, K.D., Thornton, C., Adams, M.J., (2002). Discrete particle-continuum fluid 
modelling of gas-solid fluidised beds. Chemical Engineering Science, 57, 2395-2410.

Kaneko, Y., Shiojima, T., Horio, M., (1999). DEM simulation of fluidized beds for gas-phase olefin polymerization. Chemical Engineering Science, 54, 5809-5807.

Kawaguchi, T., Sakamoto, M., Tanaka, T., Tsuji, Y., (2000). Quasi-three-dimensional numerical simulation of spouted beds in cylinder. Powder Technology, 109, 3-12.

Ketterhangen, W.R., Curtis, J.S., Wassgren, C.R., Hancock, B.C., (2008). Modeling granular segregation in flow from quasi-three-dimensional, wedge-shaped hoppers. Powder Technology, 179, 126-143.

Mio, H., Shimosaka, A., Shirakawa, Y., Hidaka, J., (2005). Optimum Cell Size for Contact Detection in the Algorithm of Discrete Element Method. Journal of Chemical Engineering of Japan, 38, 969-975.

Mio, H., Matsuoka, Y., Shimosaka, A., Shirakawa, Y., Hidaka, J., (2006a). Analysis of Developing Behavior in Two-Component Development System by Large-Scale Discrete Element Method. Journal of Chemical Engineering of Japan, 39, 1137-1144.

Mio, H., Shimosaka, A., Shirakawa, Y., Hidaka, J., (2006b). Optimum Cell Condition for Contact Detection Having Large Particle Size Ratio in Discrete Element 
Method. Journal of Chemical Engineering of Japan, 39, 409-416.

Mio, H., Yamamoto, K., Shimosaka, A., Shirakawa, Y., Hidaka, J., (2007a). Modeling of Solid Particle Flow in Blast Furnace Considering Actual Operation by Large-scale Discrete Element Method. ISIJ International, 47, 1745-1752.

Mio, H., Kano, J., Saito, F., Ito, M., (2007b). Estimation of liner design in a tube mill by Discrete Element Method. Journal of MMIJ, 123, 97-102.

Mio, H., Shimosaka, A., Shirakawa, Y., Hidaka, J., (2007c). Program optimization for large-scale DEM and its effects of processor and compiler on the calculation speed. Journal of the Society of Powder Technology, Japan, 44, 206-211.

Mio, H., Shimosaka, A., Shirakawa, Y., Hidaka, J., (2007d). Cell Optimization for Fast Contact Detection in the Algorism of Discrete Element Method. Advanced Powder Technology, 18, 441-453.

Mio, H., Matsuoka, Y., Shimosaka, A., Shirakawa, Y., Hidaka, J., (2007e). Speed-up Method for Modeling of Magnetic Brush in Two-component Development System by using Discrete Element Method. Journal of the Imaging Society of Japan, 46, 95-102.

Moreno, R., Ghadiri, M., Antony, S.J., (2003). Effect of the impact angle on the breakage of agglomerates: A numerical study using DEM. Powder Technology, 
$130,132-137$.

Rajamani, R.K., Mishra, B.K., Venugopal, R., Datta, A., (2000). Discrete element analysis of tumbling mills. Powder Technology, 109, 105-112.

Severens, I.E.M., van de Ven, A.A.F., Wolf, D.E., Mattheji, R.M.M., (2006). Discrete element method simulations of toner behavior in the development nip of the Ocè Direct Imaging print process. Granular Matter, 8, 137-150.

Taberlet, N., Richard, P., Hinch, E.J., (2006). S shape of a granular pile in a rotating drum. Physical Review E, 73, 050301.

Thornton, C., Liu, L., (2004). How do agglomerates break?. Powder Technology, $143-144,110-116$.

Yang, R.Y., Zou, R.P., Yu, A.B., (2003). Microdynamic analysis of particle flow in a horizontal rotating drum. Powder Technology, 130, 138-146.

Yuu, S., Umekage, T., Miyahara, T., (2005). Prediction of Stable and Unstable Flows in Blast Furnace Raceway Using Numerical Simulation Methods for Gas and Particles. ISIJ International, 45, 1406-1415.

Zhou, Z., Zhu, H., Yu, A.B., Wright, B., Pinson, D., Zulli, P., (2005). Discrete Particle Simulation of Solid Flow in a Model Blast Furnace. ISIJ International, 45, 1828-1837. 
Zhu, H.P., Yu, A.B., Wu, Y.H., (2006). Numerical investigation of steady and unsteady state hopper flows. Powder Technology, 170, 125-134. 


\section{Figure Captions}

Figure $1 \quad$ Relation between the computing time and calculation step

Figure 2 Relation between the number of contact force calculations and the calculation step

Figure 3 Schematic diagram of particles in charged bed

Figure $4 \quad$ Relation between vertical particle position and calculation step

Figure $5 \quad$ Relation between relative displacement of particle and calculation step

Figure $6 \quad$ Snapshots of charging behavior to hopper bin

Figure7 Relation between the computing time and calculation step

Figure $8 \quad$ Relation between the number of contact force calculations and calculation step

Figure 9 Packing fraction for each condition

I). Original, II). $\tau=100000, \Psi_{i}=3$, III). $\tau=100000, \Psi_{i}=2$,

IV). $\left.\left.\tau=100000, \Psi_{i}=1, \mathrm{~V}\right) . \tau=50000, \Psi_{i}=3, \mathrm{VI}\right) . \tau=50000, \Psi_{i}=2$,

VII). $\tau=30000, \Psi_{i}=3$, VIII). $\tau=20000, \Psi_{i}=3$,

Figure 10 Snapshots of discharging behavior from hopper

Figure 11 Relation between the percentage of unmoved particles and 
normalized calculation step

Figure 12 Relation between the computing time and calculation step

Figure 13 Snapshots of charged particles in the surge hopper

Figure $14 \quad$ Mapping of mass fraction in the surge hopper

Figure 15 Distribution of mass fraction of particles in surge hopper 


\section{Notations}

$F \quad$ : Force

$[\mathrm{N}]$

$F_{\mathrm{n}} \quad$ : Compressive force

$F_{\mathrm{t}} \quad:$ Shear force

g : Gravitational acceleration

$\left[\mathrm{m} / \mathrm{s}^{2}\right]$

I : Moment of inertia

$\left[\mathrm{kg} \cdot \mathrm{m}^{2}\right]$

$K \quad$ : Spring coefficient

$[\mathrm{N} / \mathrm{m}]$

M : Moment

$[\mathrm{N} \cdot \mathrm{m}]$

$m \quad$ : Mass of a particles

$[\mathrm{kg}]$

$n \quad:$ Number of particles

$[-]$

$n_{\mathrm{f}} \quad:$ Number of contact force calculations

$[-]$

$\mathbf{n}_{i j} \quad:$ Normal unit vector from $i$-th particle to $j$-th one

$[-]$

$P_{\mathrm{u}} \quad$ : Percentage of number of unmoved particles

$p \quad$ : Wall stress on the hopper

$Q \quad$ : Frequency

$r \quad$ : Particle radius

$t \quad$ : Time

$t_{c} \quad$ : Computing time 
$t_{\text {fin }} \quad$ : Number of calculation steps for finish the charging

$t_{i} \quad$ : Calculation step

$\mathbf{t}_{i j} \quad$ : Tangential unit vector from $i$ th particle to $j$-th one

$\Delta u \quad$ : Displacement

$u_{z} \quad$ : Vertical position

$\checkmark \quad$ : Velocity

W : Mass fraction

[wt\%]

Greeks

$\chi \quad:$ Relative displacement within $\tau$ steps

$[-]$

$\phi \quad$ : Angular displacement

[rad]

$\eta \quad$ : Damping coefficient

$[\mathrm{N} \cdot \mathrm{s} / \mathrm{m}]$

$\varphi \quad$ : Packing fraction

$[-]$

$\mu \quad$ : Frictional coefficient

$[-]$

$\tau \quad:$ Number of calculation steps for accumulating displacement

$\omega \quad$ : Angular velocity

$\Psi \quad$ : Counter for determination of ignoring 
Table 1 Computing time for calculation of charging to hopper bin

\begin{tabular}{|c|c|c|c|}
\hline$\tau$ & $\Psi_{i}$ & \multicolumn{2}{|c|}{ Computing time } \\
\hline [step] & {$[-]$} & [s/8M steps] & Relative \\
\hline 100000 & 3 & 182196.8 & $48.3 \%$ \\
\hline 100000 & 2 & 163277.6 & $43.3 \%$ \\
\hline 100000 & 1 & 134387.8 & $35.6 \%$ \\
\hline 50000 & 3 & 126247.6 & $33.5 \%$ \\
\hline 50000 & 2 & 110603.5 & $29.3 \%$ \\
\hline 30000 & 3 & 88717.6 & $23.5 \%$ \\
\hline 20000 & 3 & 72339.5 & $19.2 \%$ \\
\hline \multicolumn{2}{|c|}{ Original } & 377093.1 & - \\
\hline
\end{tabular}


Table 2 Computing time for calculation of discharging from hopper, the angle of repose and the packing fraction in the container

\begin{tabular}{cccccc}
\hline$\tau$ & $\Psi_{i}$ & \multicolumn{2}{c}{ Computing time } & Angle of repose & Packing fraction \\
{$[$ step $]$} & {$[-]$} & {$[\mathrm{s} / 3$ M steps $]$} & Relative & {$[$ degree $]$} & {$[-]$} \\
\hline \hline 50000 & 3 & 164798.8 & $81.0 \%$ & 19.1 & 0.6044 \\
30000 & 3 & 151700.8 & $74.6 \%$ & 19.0 & 0.6020 \\
\hline \multicolumn{2}{c}{ Original } & 203416.5 & - & 18.8 & 0.6046 \\
\hline
\end{tabular}


Table 3 Relative computing time under different size of container

\begin{tabular}{cccc}
\hline Container width $[\mathrm{mm}]$ & 44.0 & 62.8 & 81.6 \\
Relative computing time & $71.3 \%$ & $74.6 \%$ & $79.4 \%$ \\
\hline
\end{tabular}




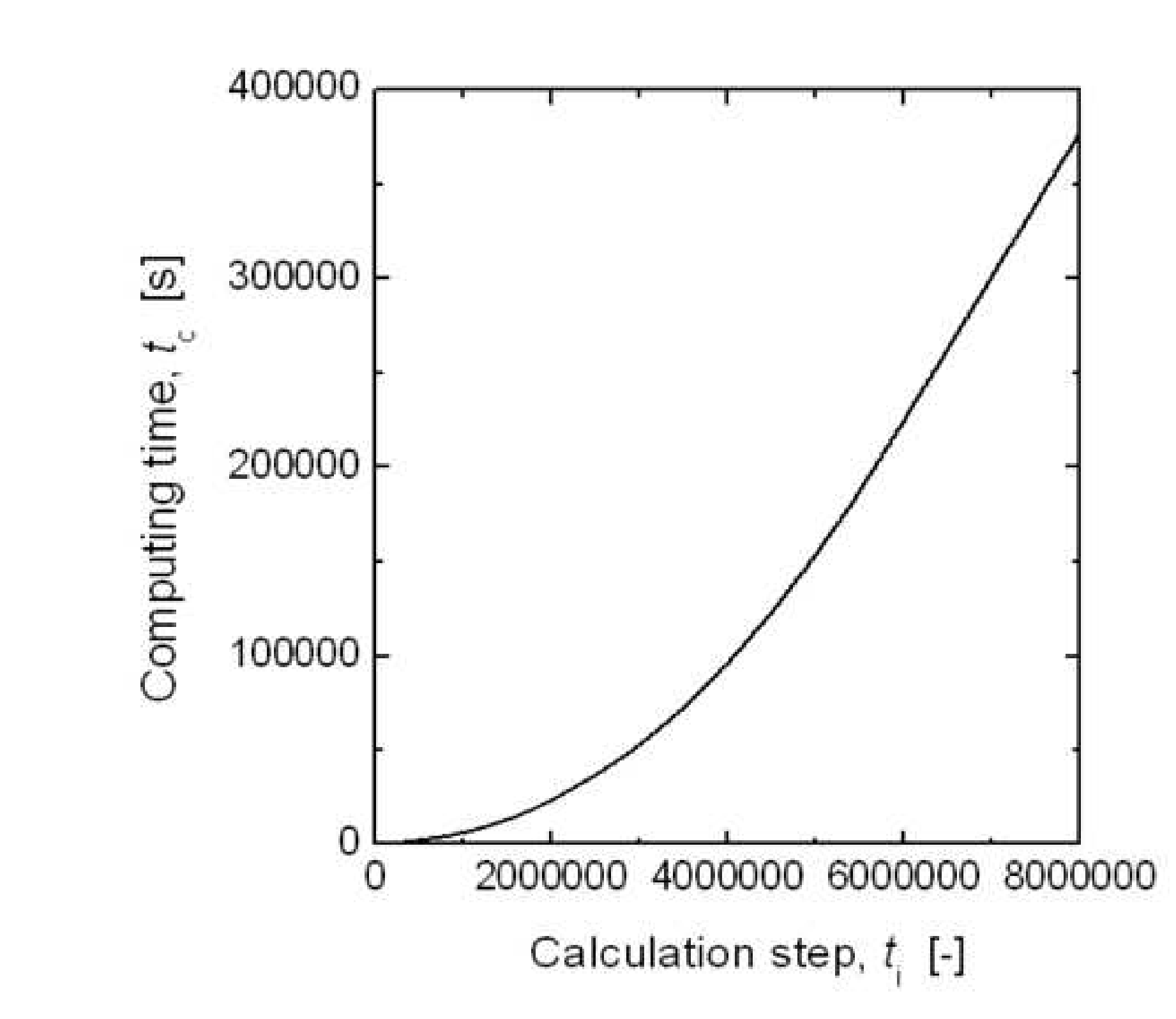

Figure 1

\section{Figure 1}

(
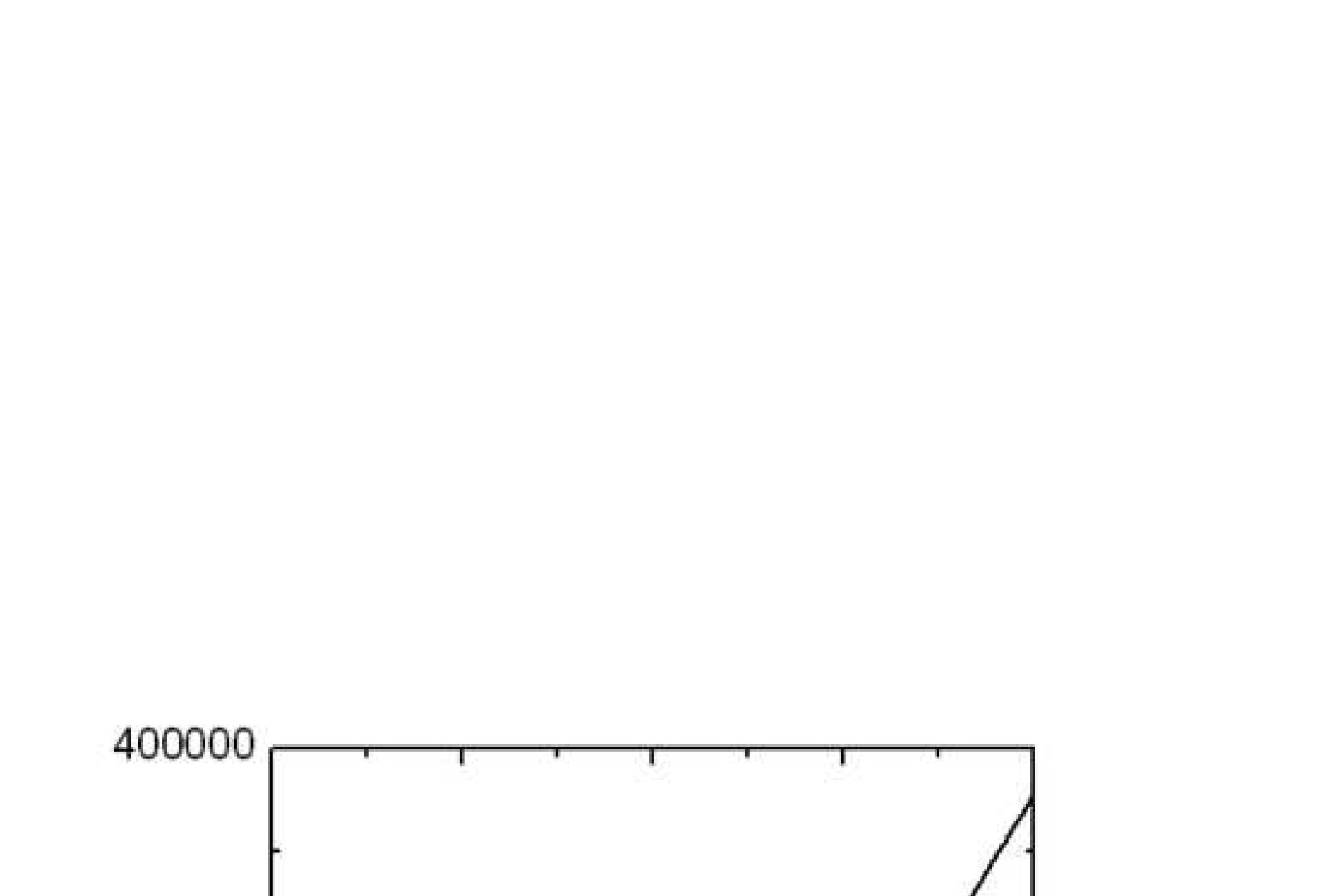


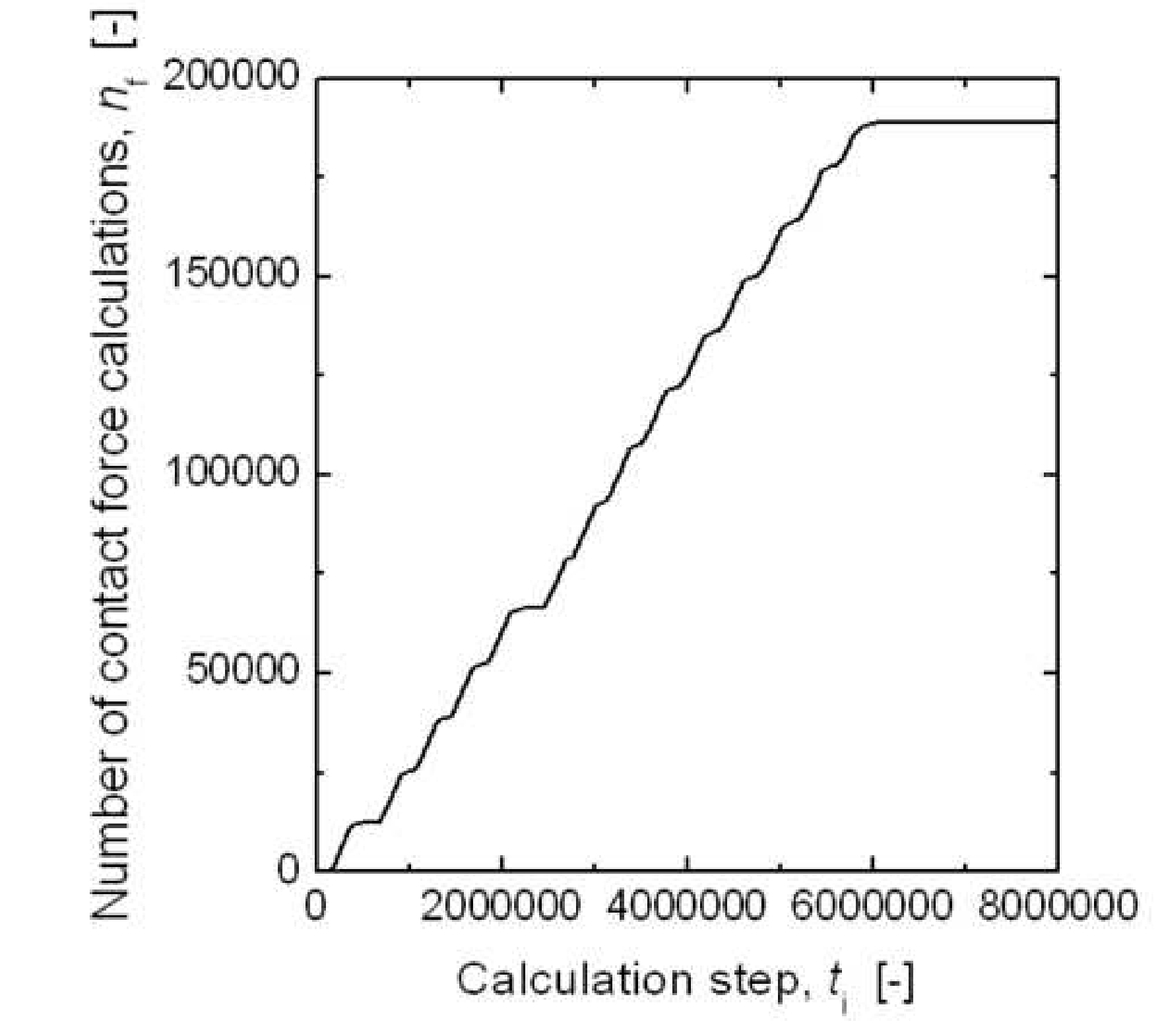

Figure 2

Figure 2

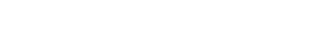
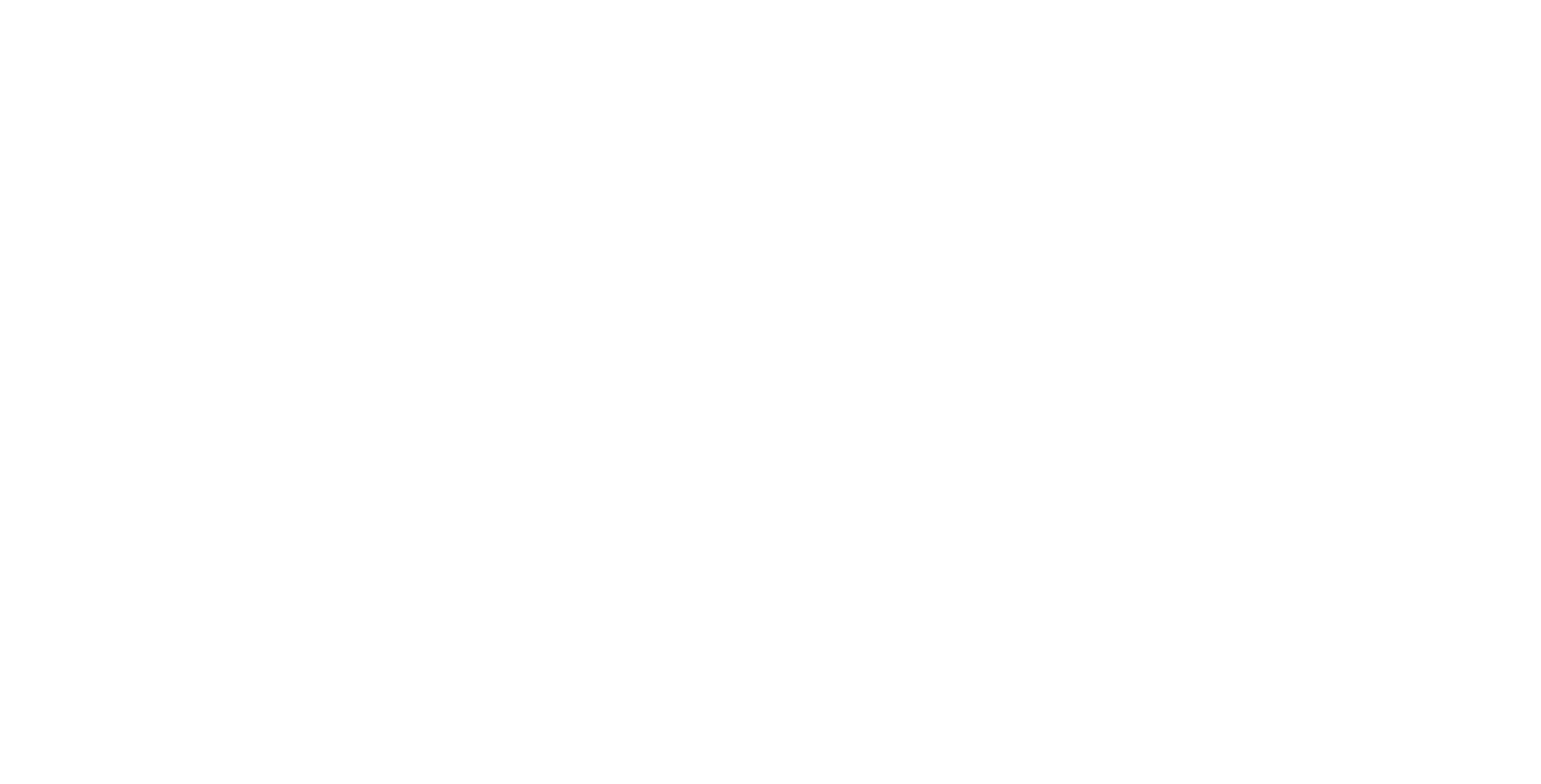
,

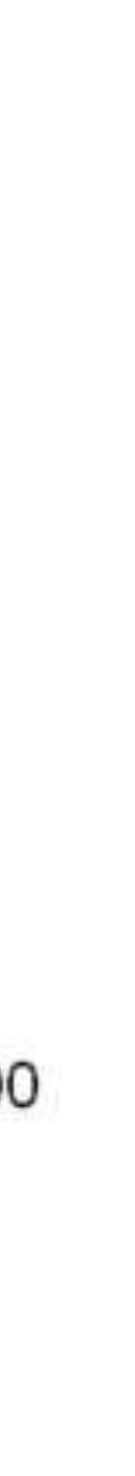




$$
\mathbf{F}_{i}=\sum_{k} \mathbf{F}_{k, i}+\mathbf{F}_{\mathrm{g}, i} \approx 0
$$

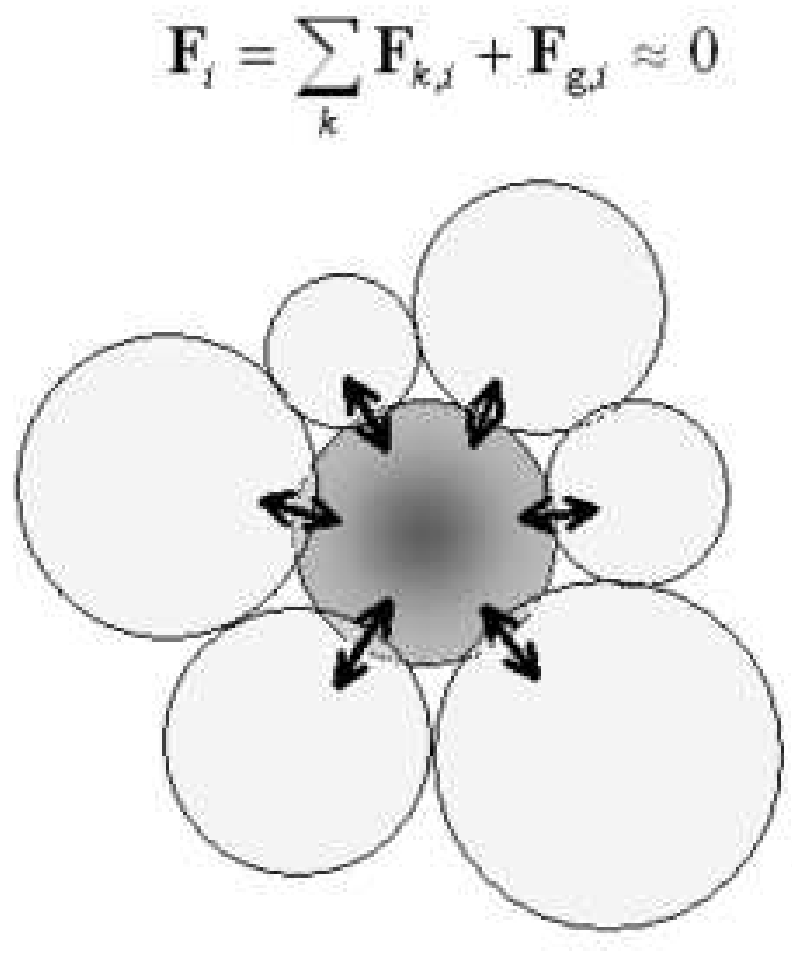

Charged bed

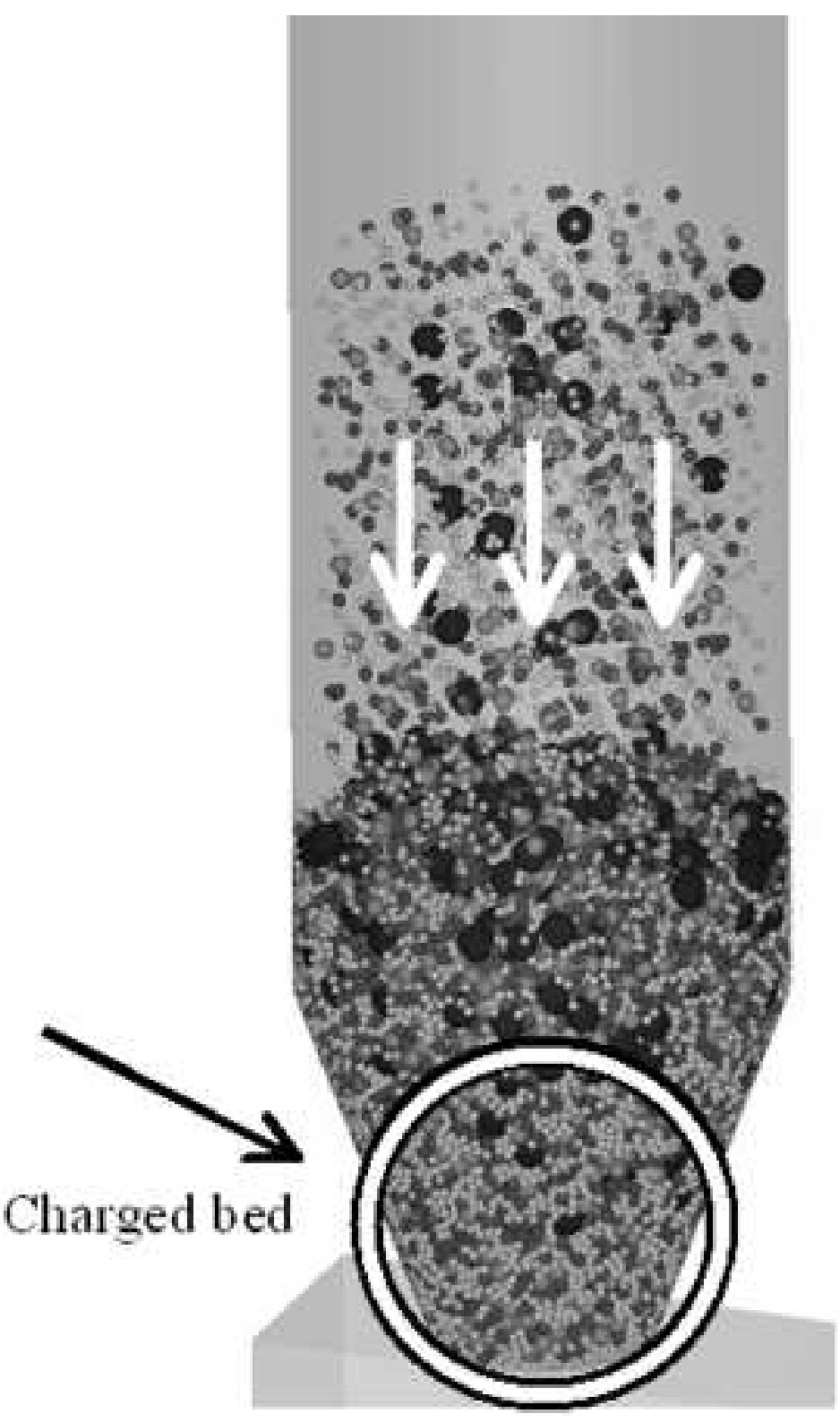

Figure 3

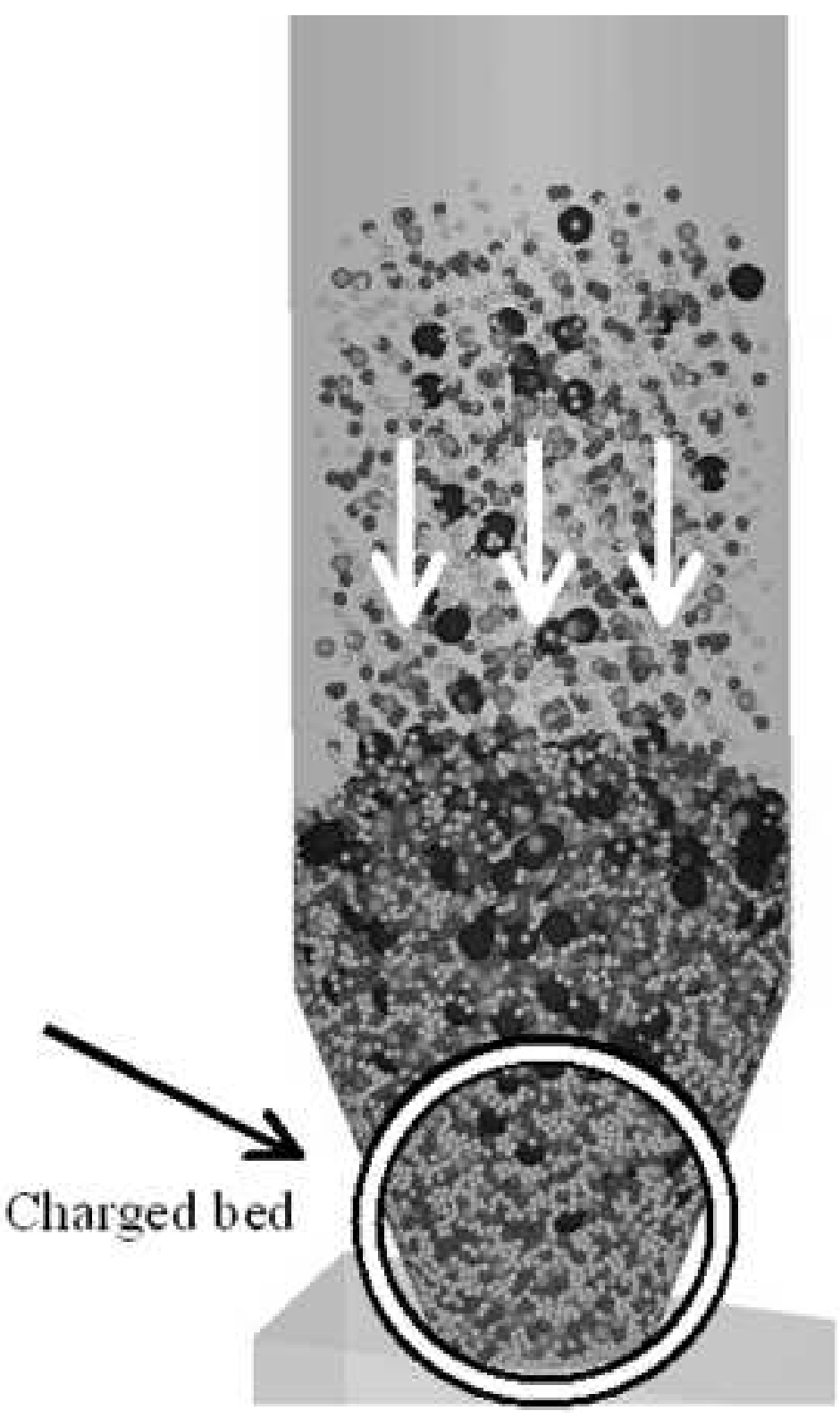

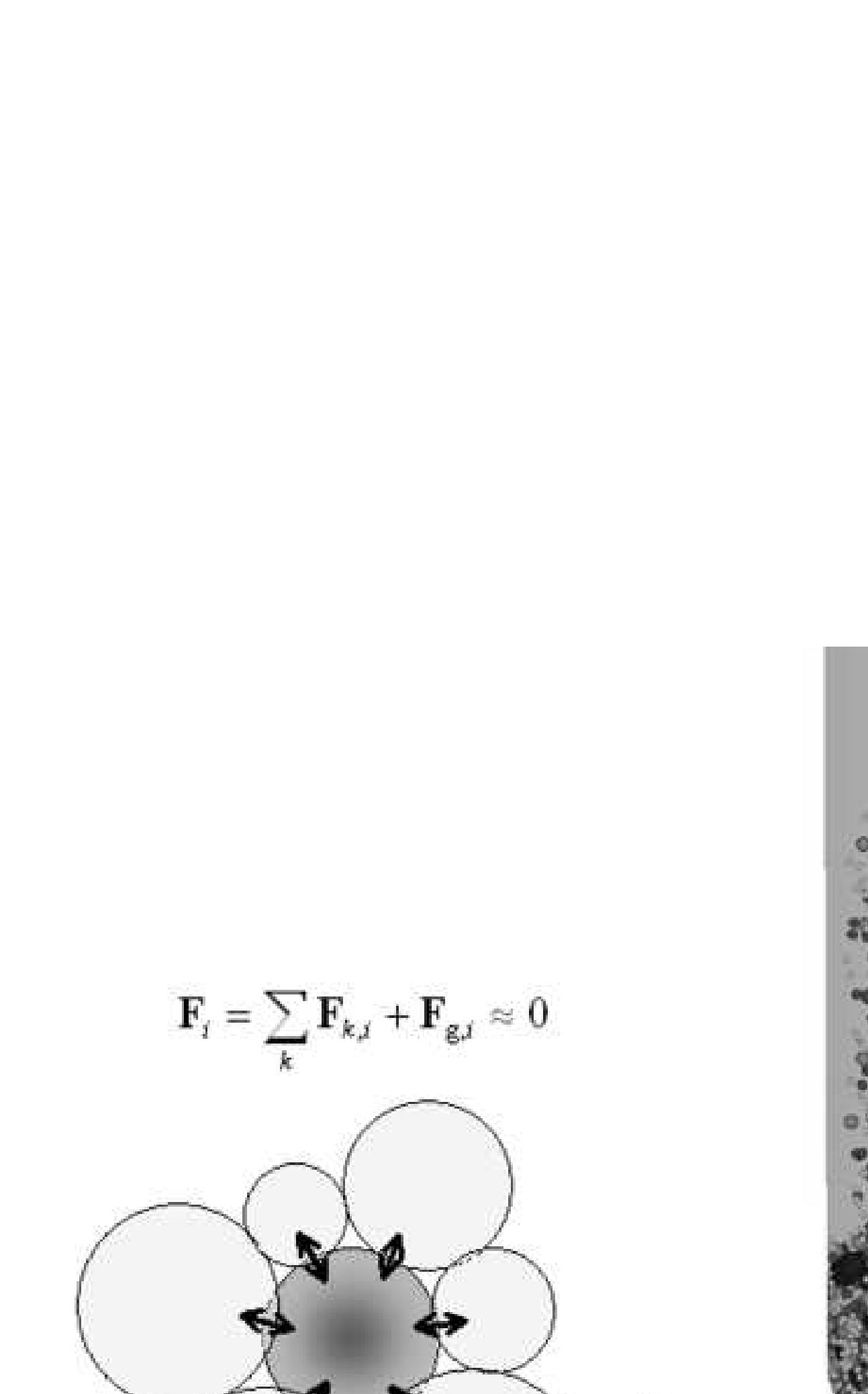




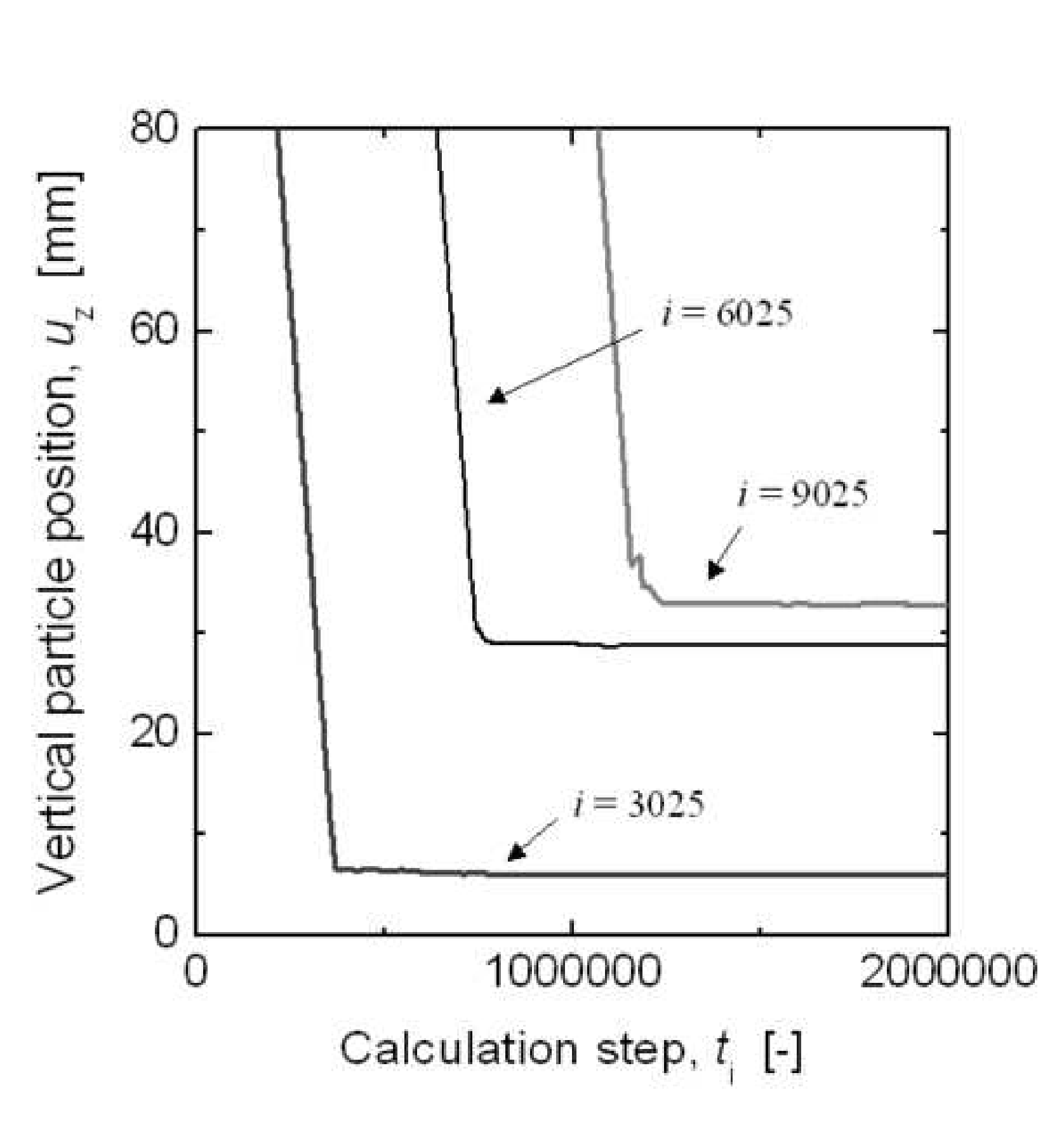

Figure 4

(⿸丆口

4




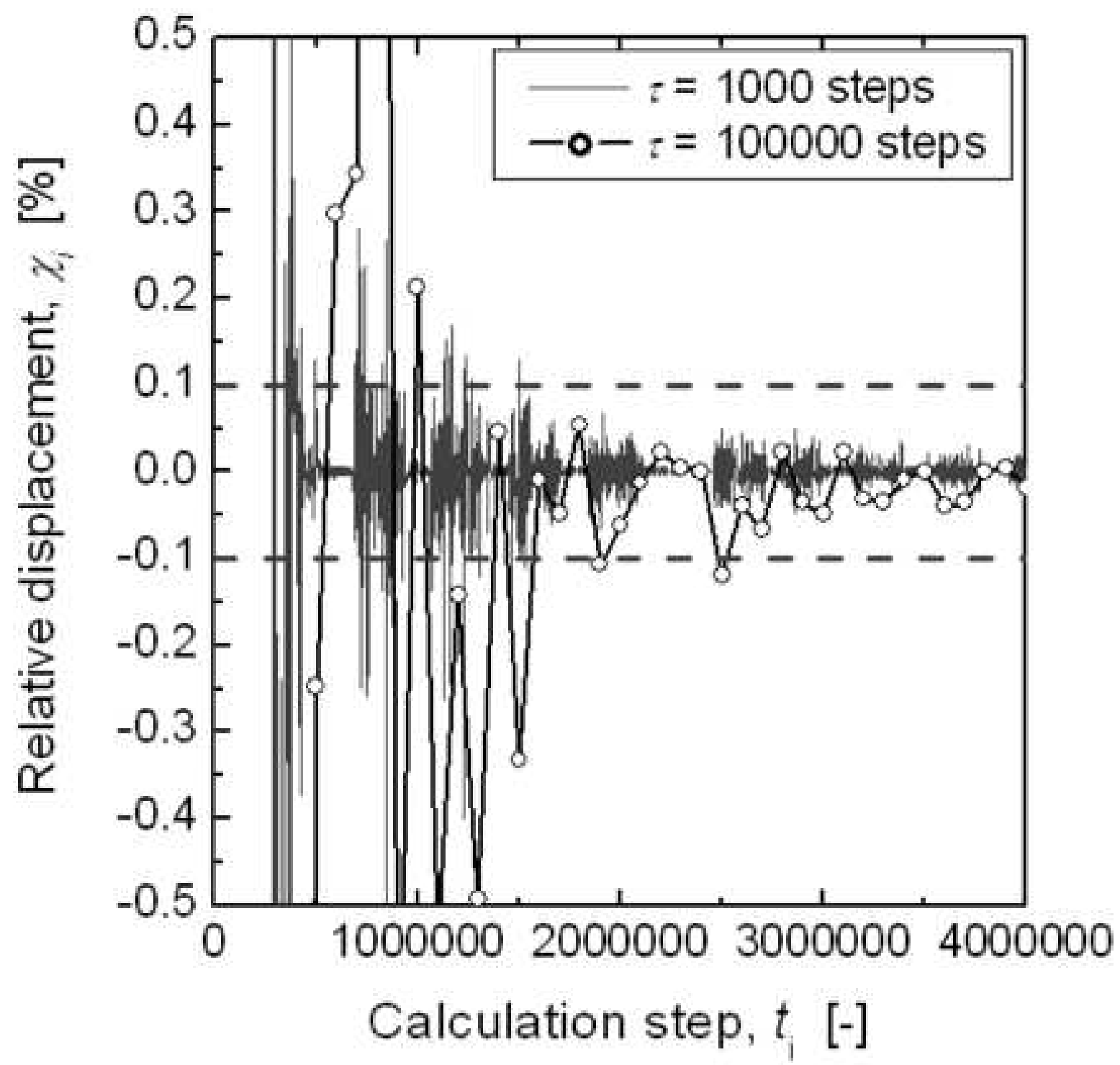



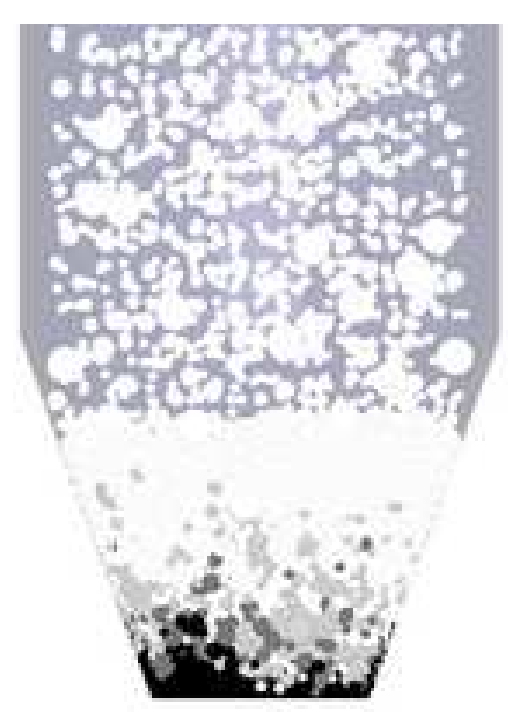

(a) $1.5 \mathrm{M}$ steps

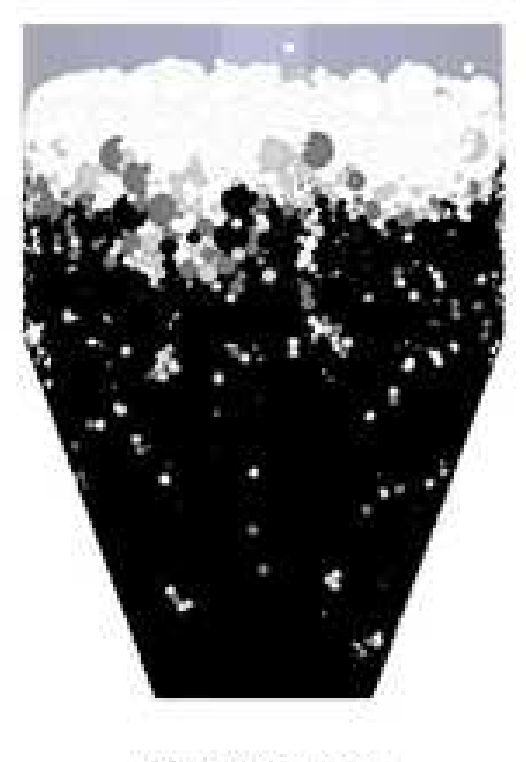

(d) $6.0 \mathrm{M}$ steps

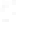

(b) $3.0 \mathrm{M}$ steps

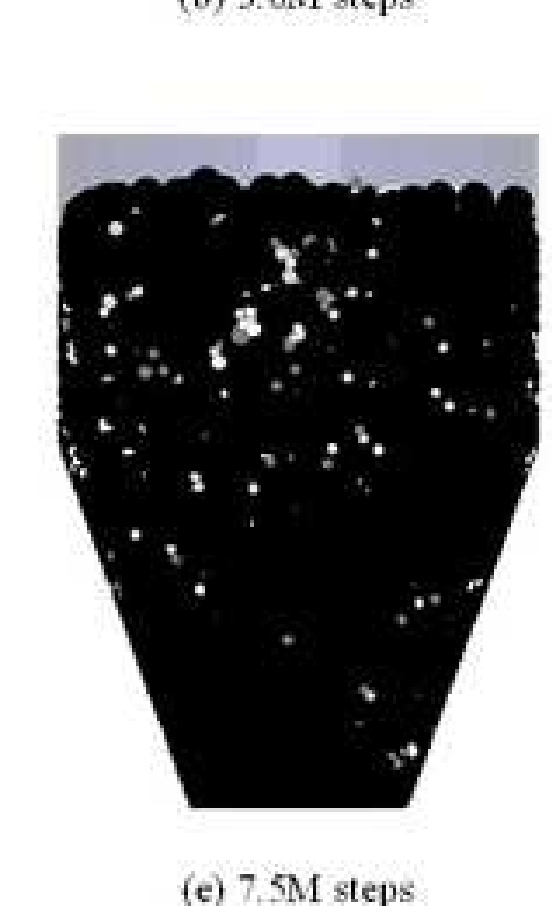

(e) $7,5 \mathrm{M}$ steps

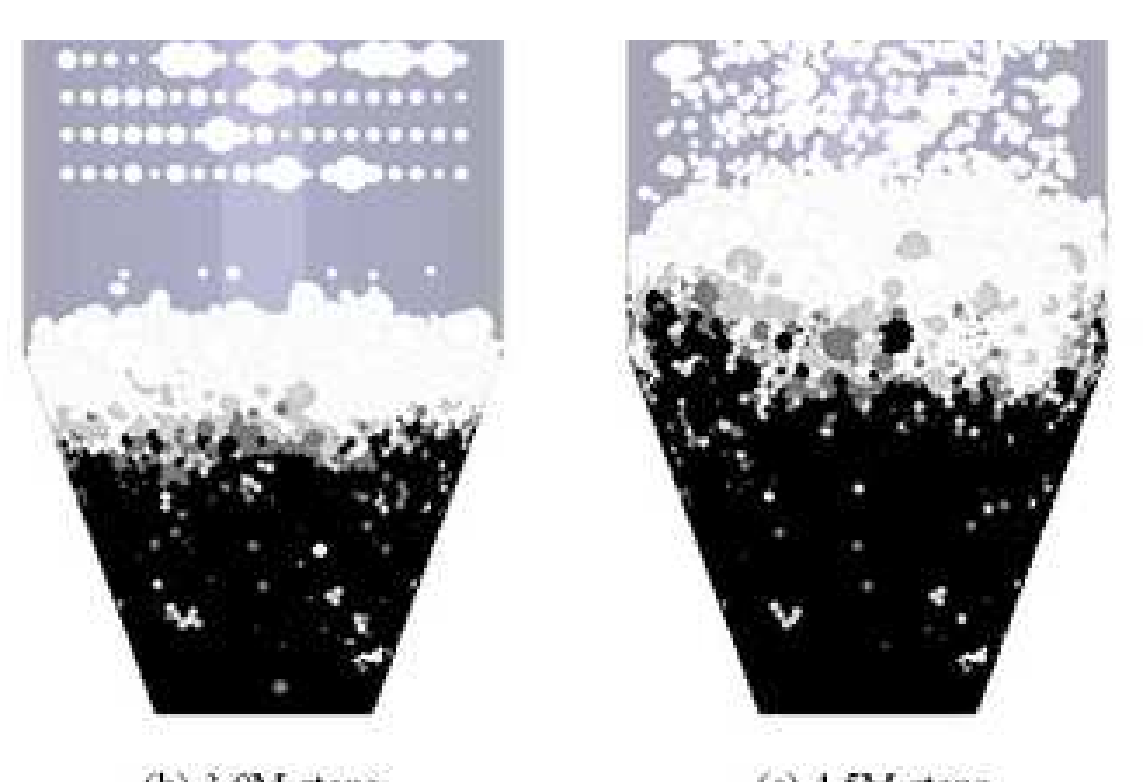

(c) $4.5 \mathrm{M}$ steps:$$
\text { . }
$$

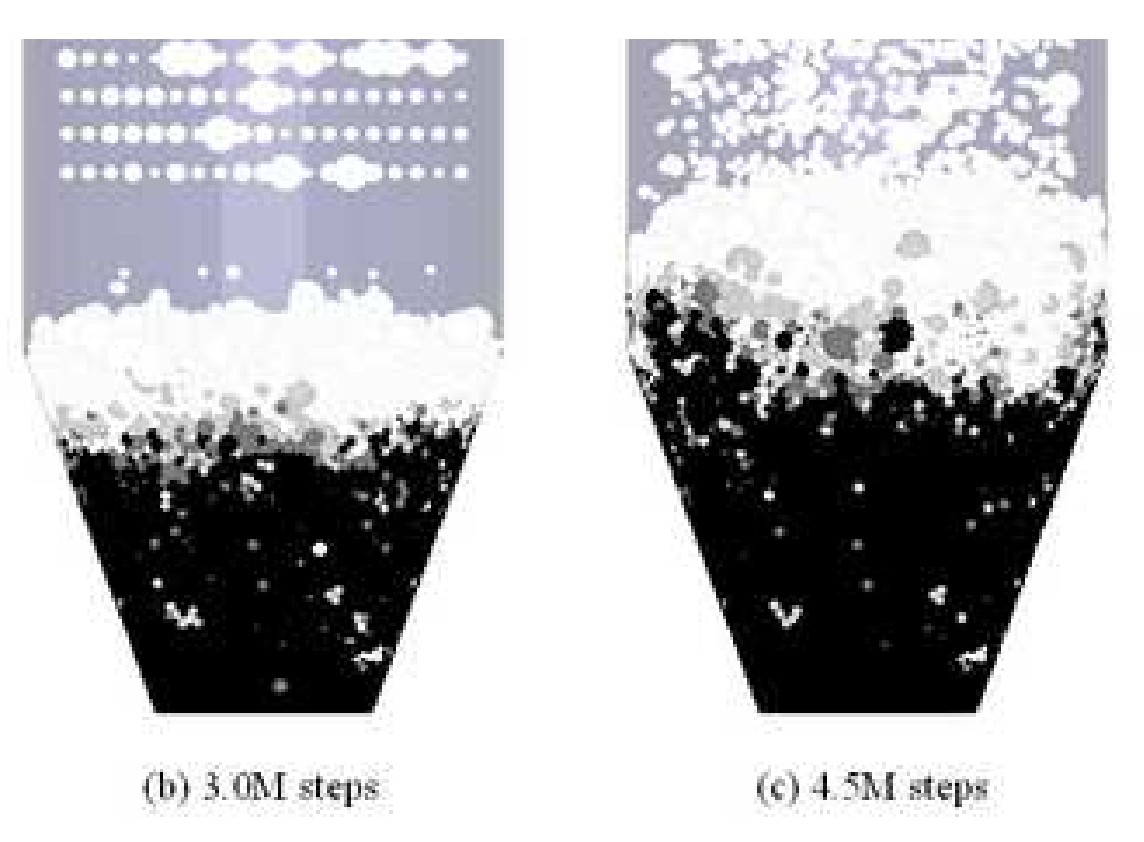

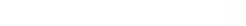

Figure 6

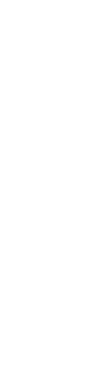




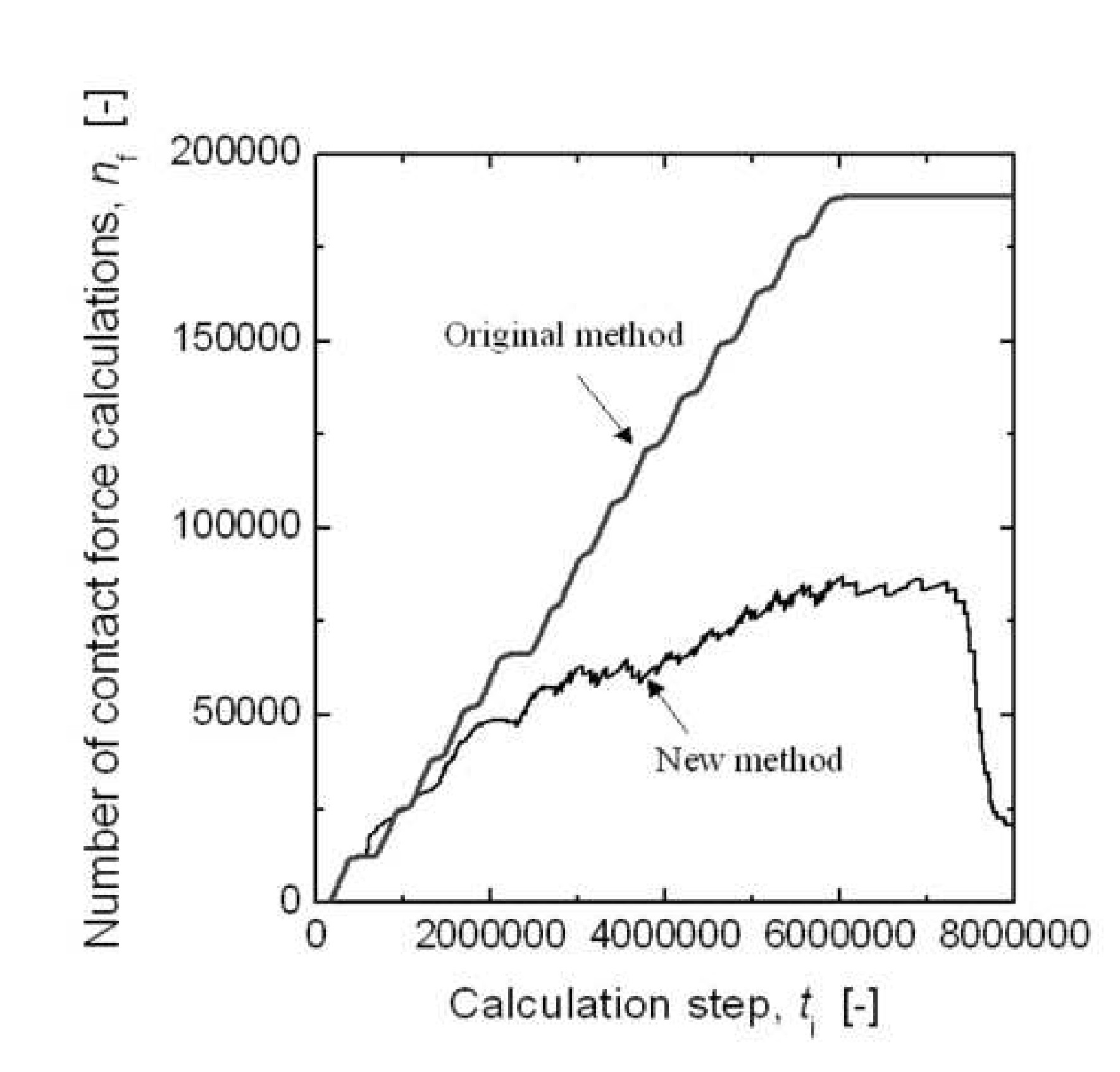

Figure 8

8

8

Figure 8

(1)

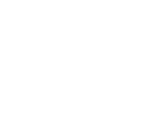

(
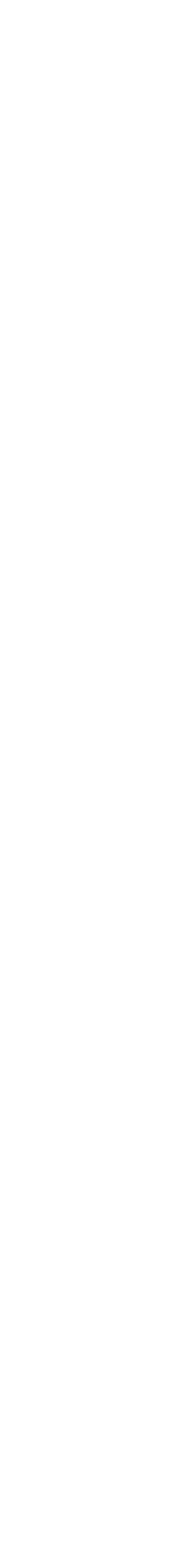

.




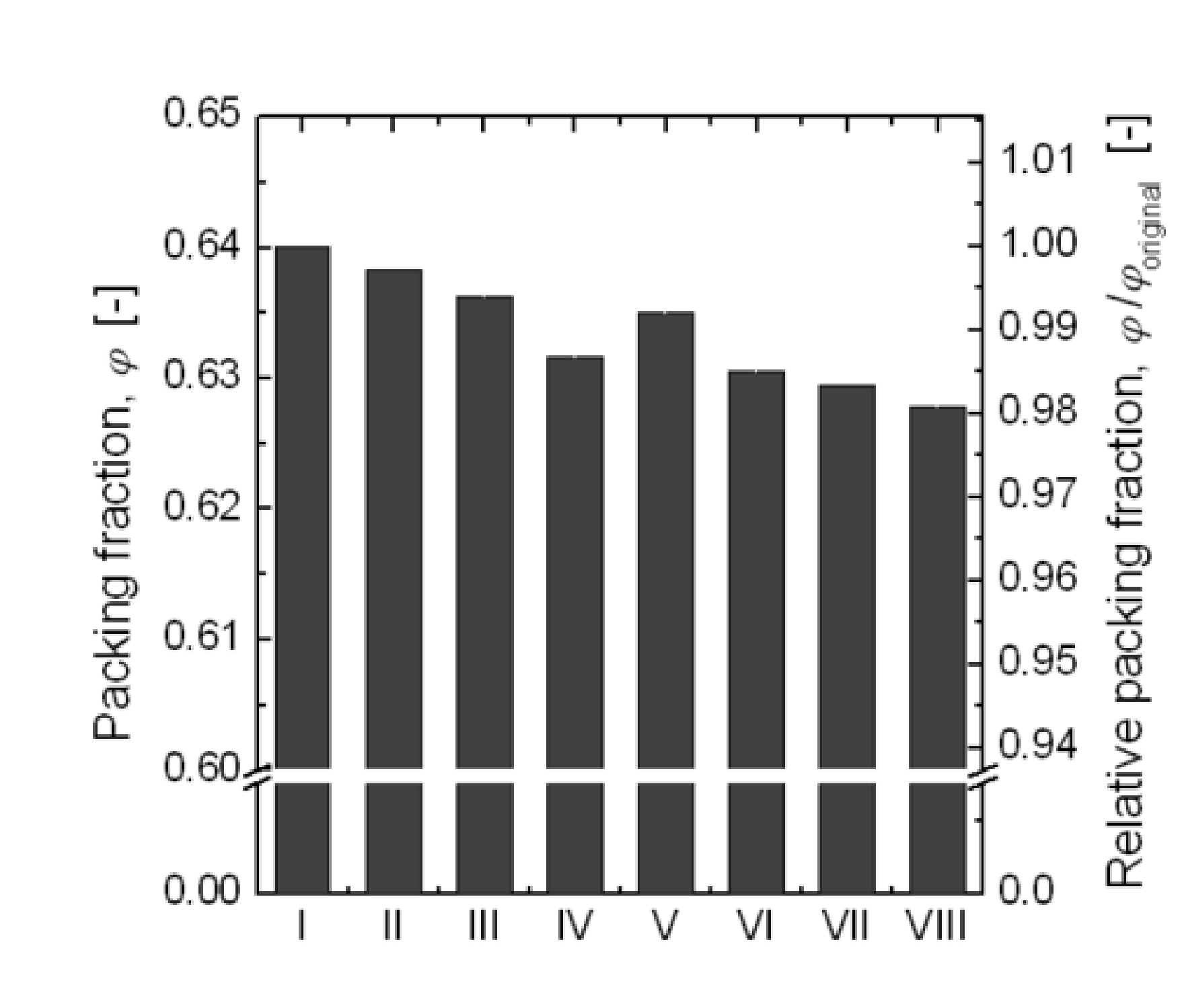

Figure 9

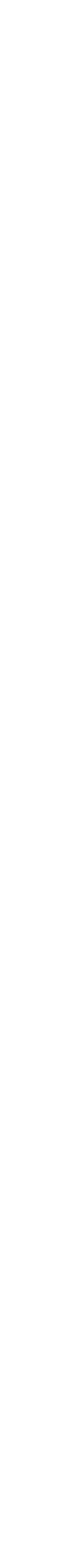

igure 9

C
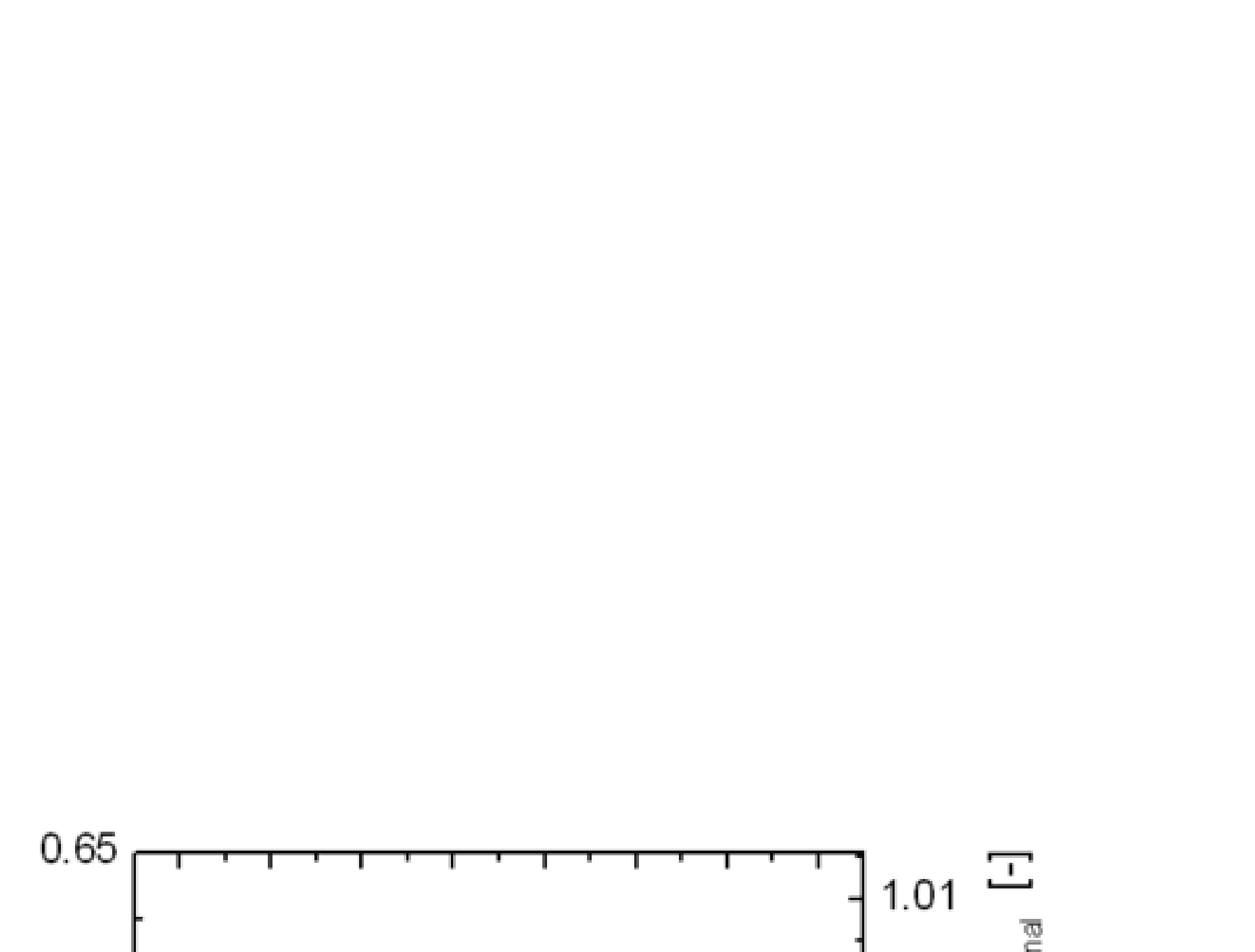

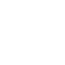

(1)
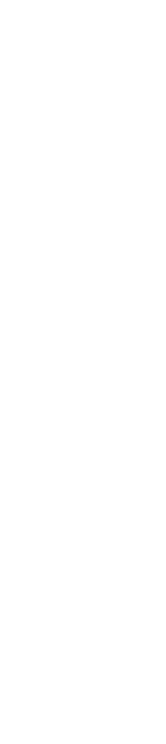

$$
\text { . }
$$
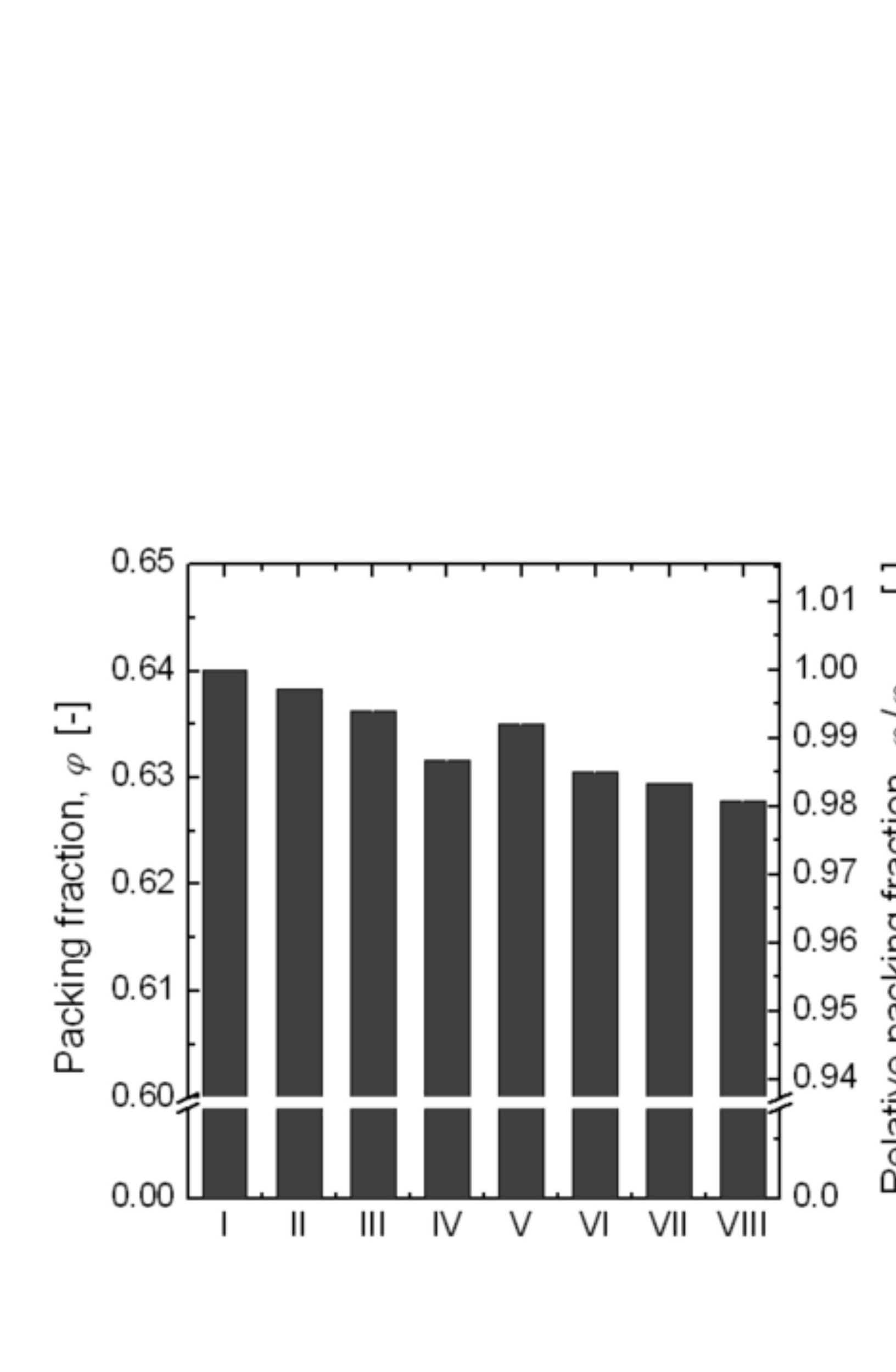


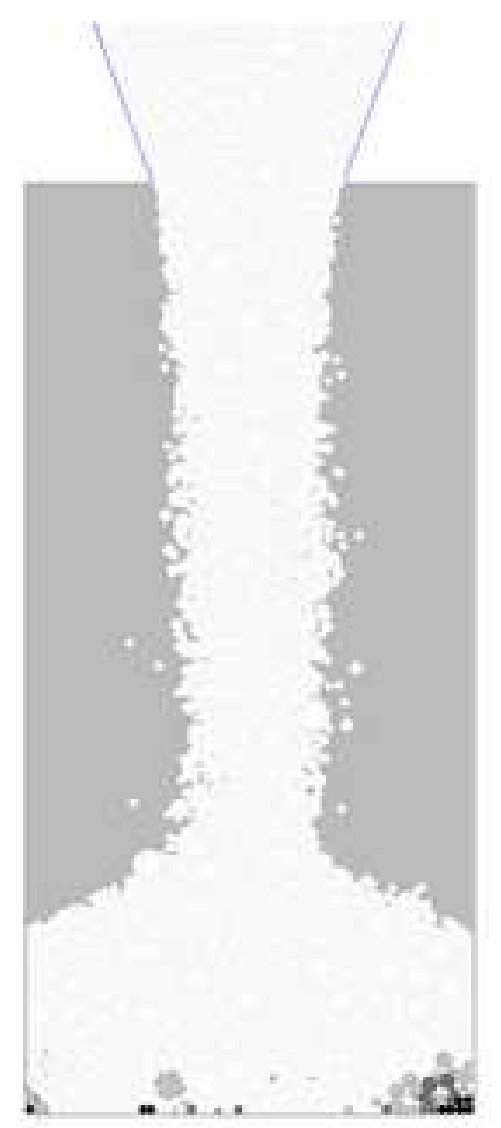

(a) $1.0 \mathrm{M}$ steps

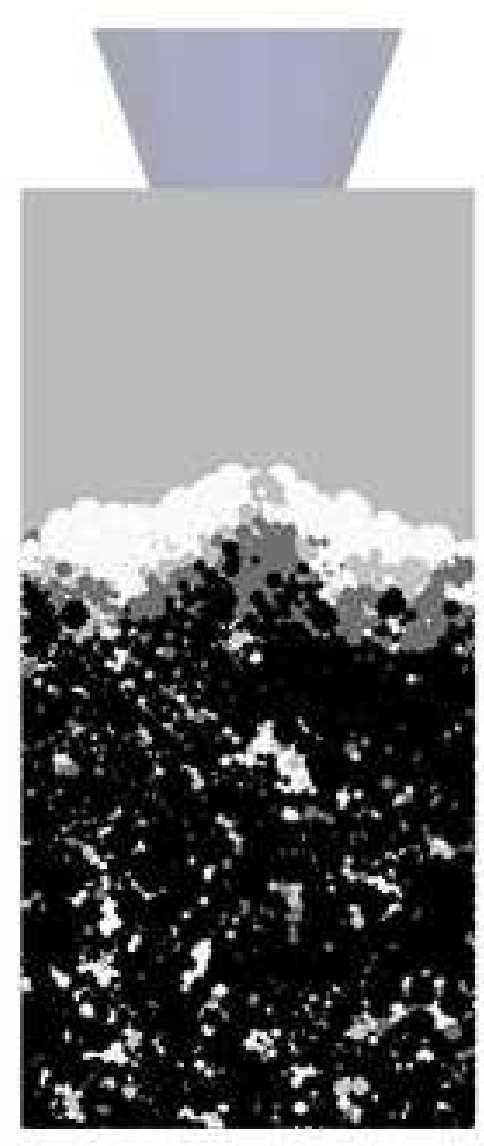

(d) $2.5 \mathrm{M}$ steps

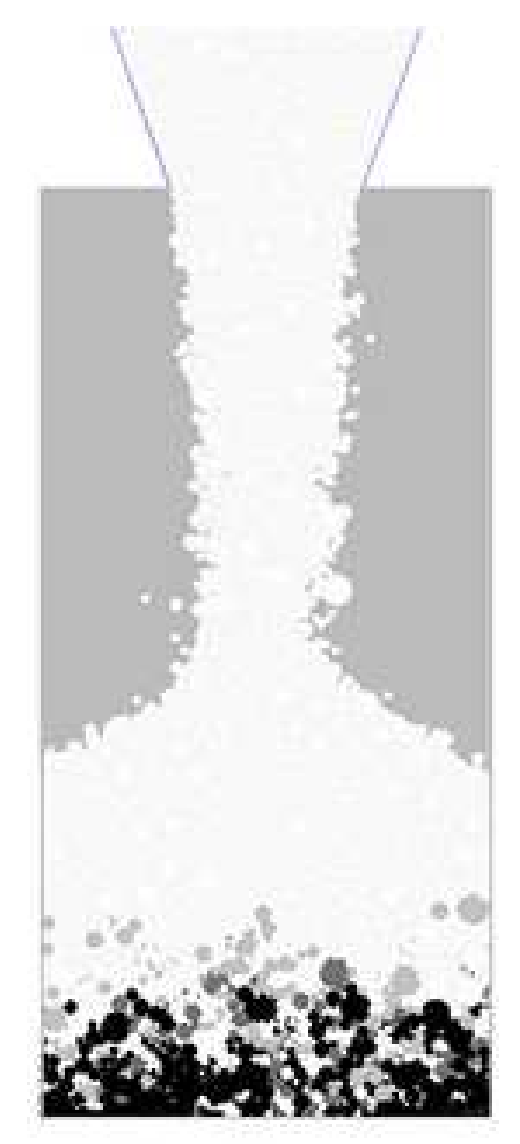

(b) $1.5 \mathrm{M}$ steps

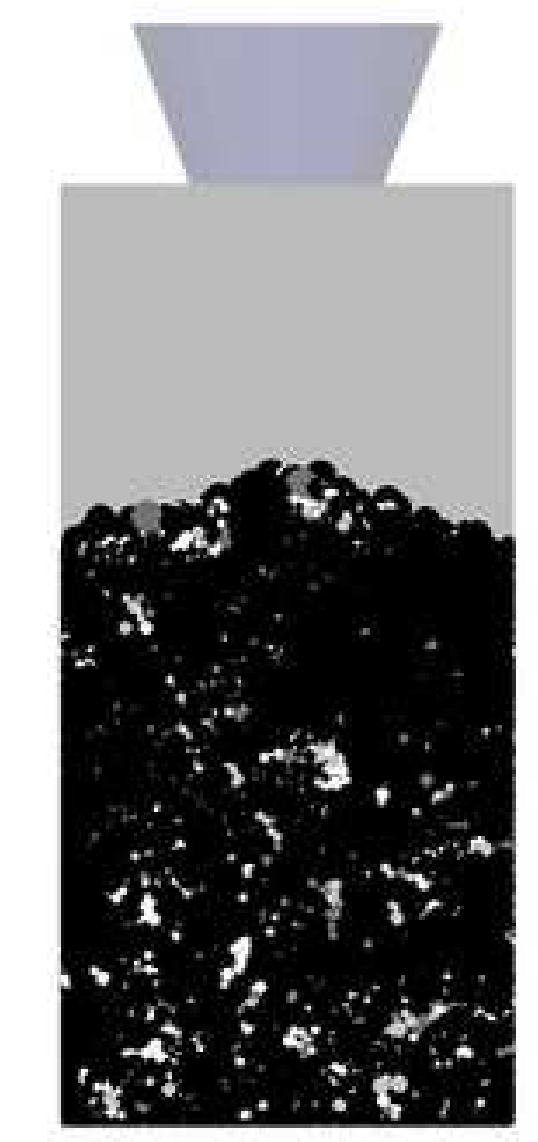

(e) $3.0 \mathrm{M}$ steps

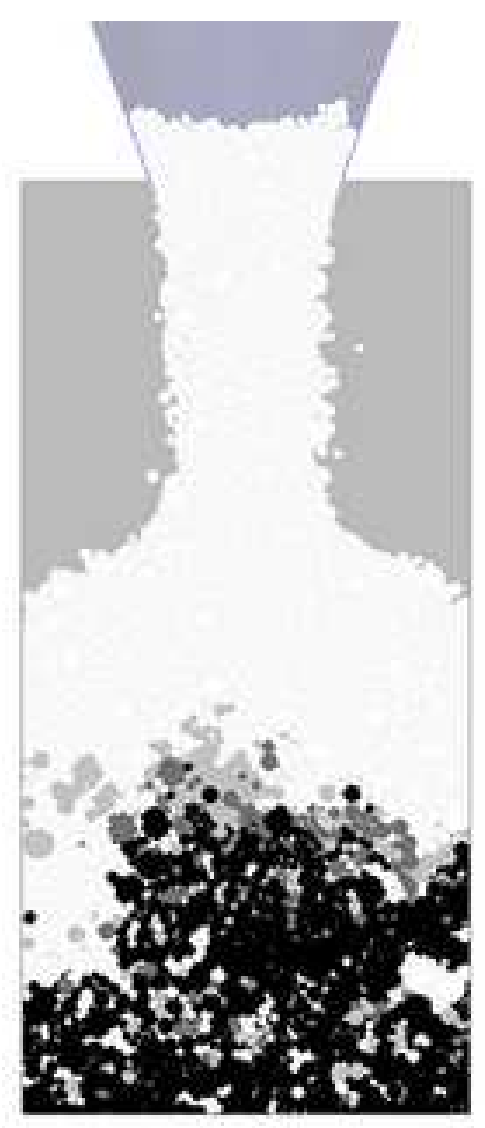

(c) $2.0 \mathrm{M}$ steps

$$
\text { . }
$$




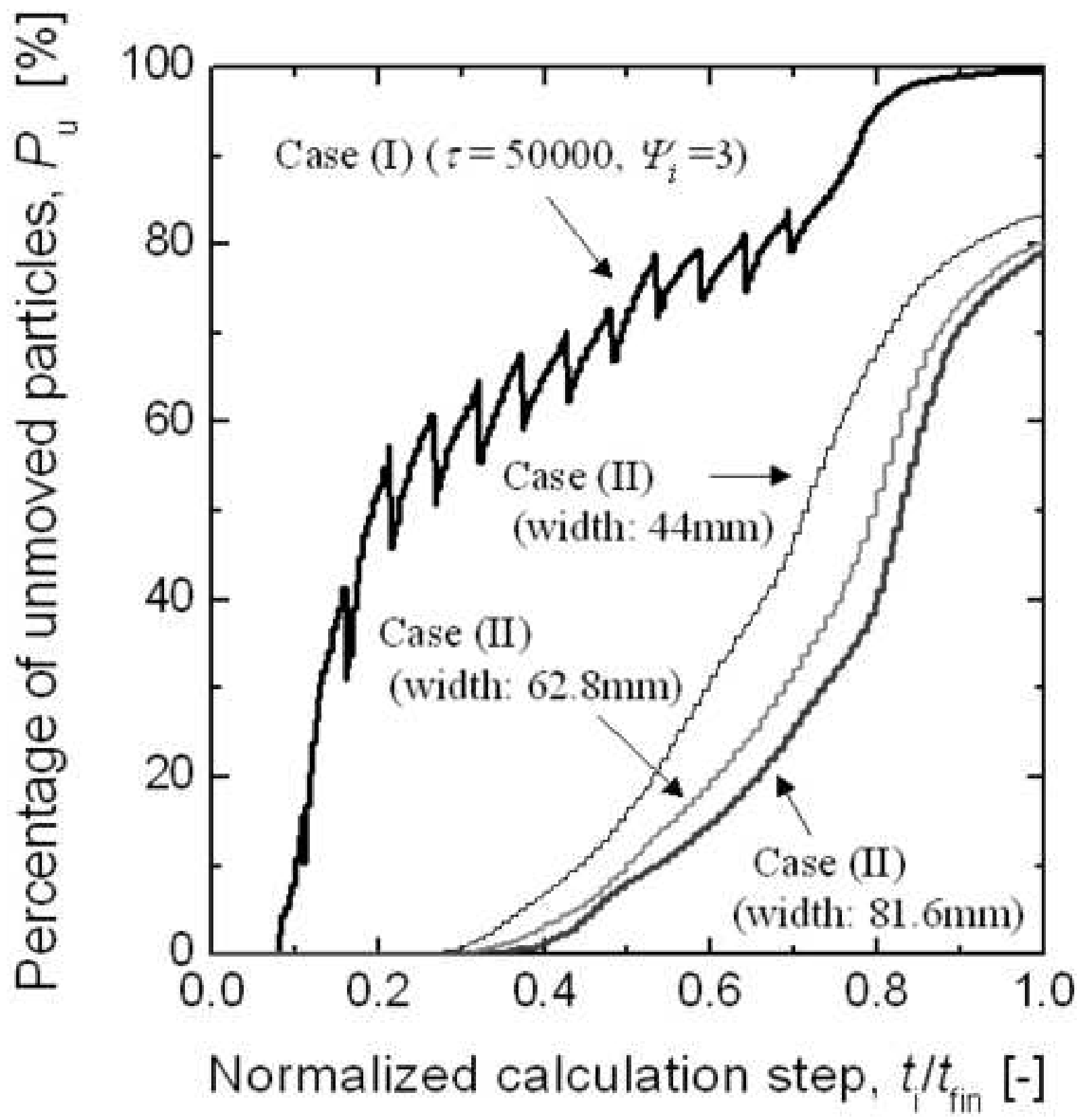



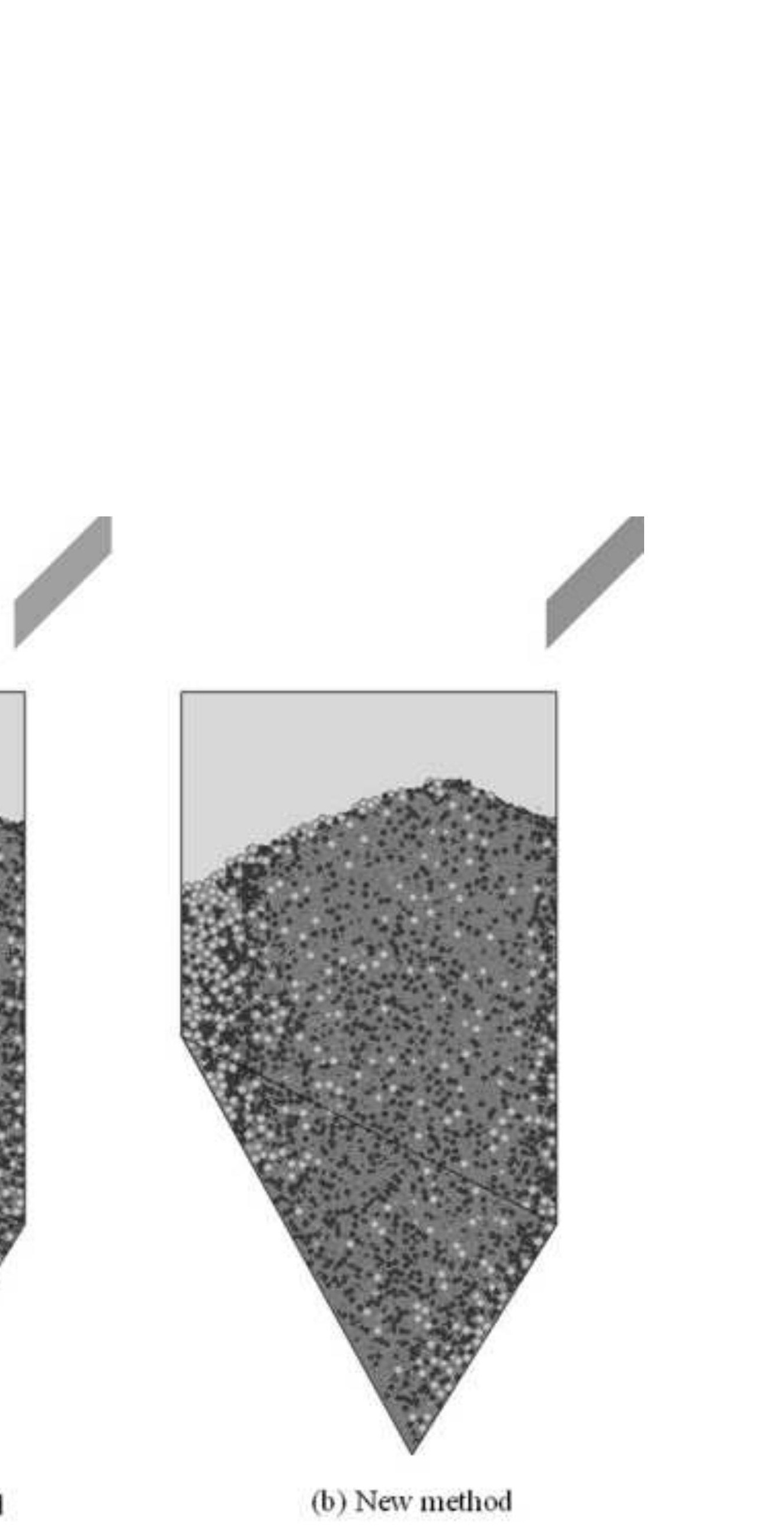

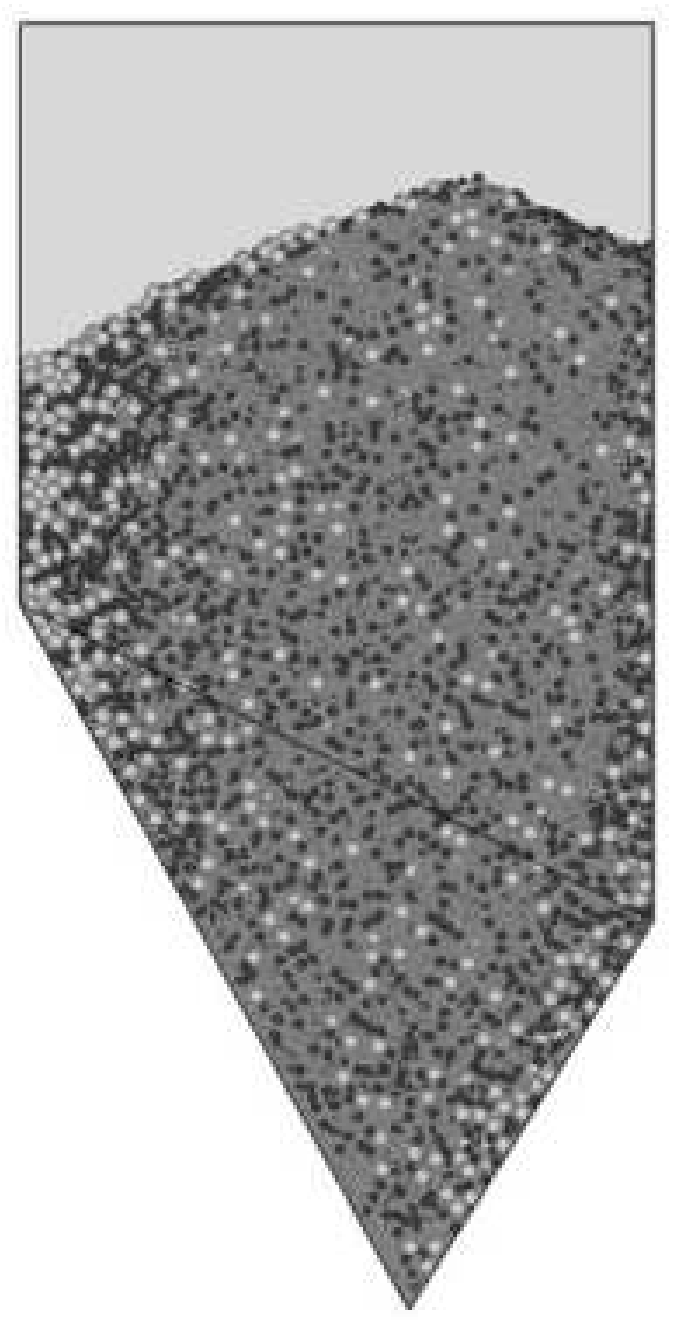

(a) Original method

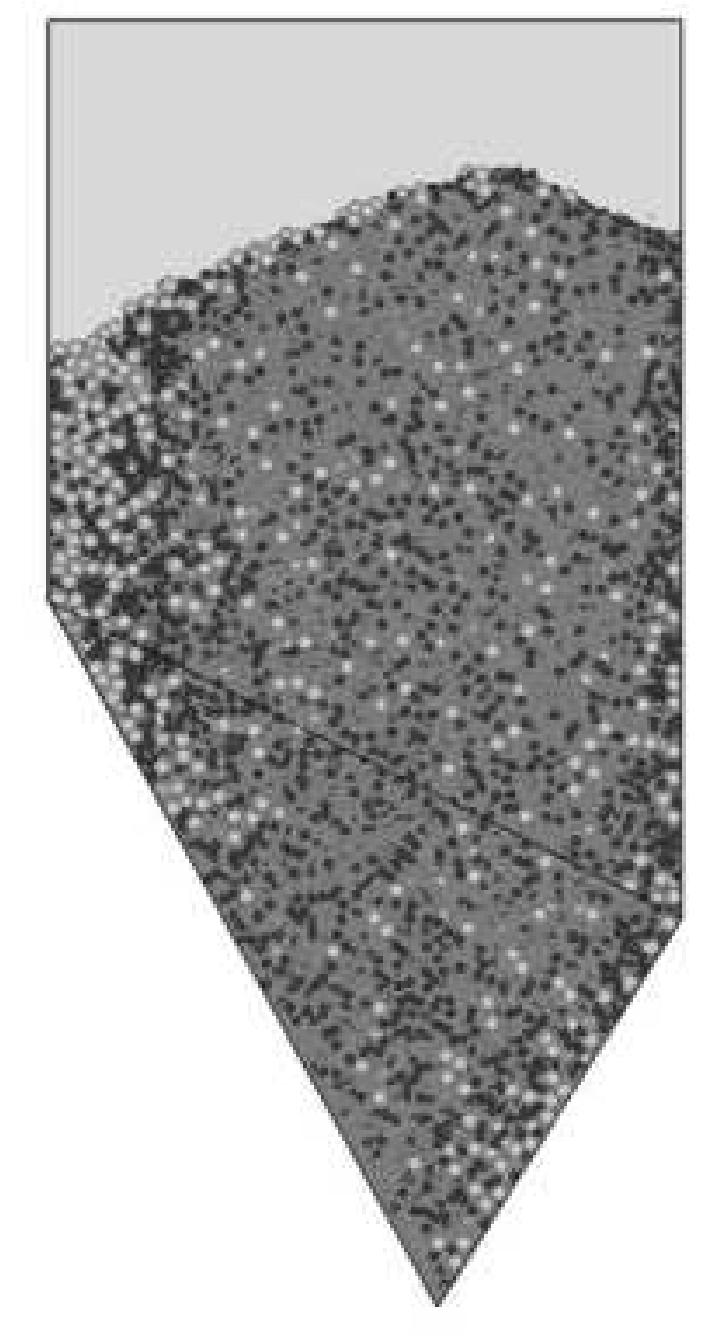

(b) New method

(b) New method

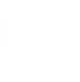

\title{
Figure 13
}

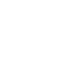
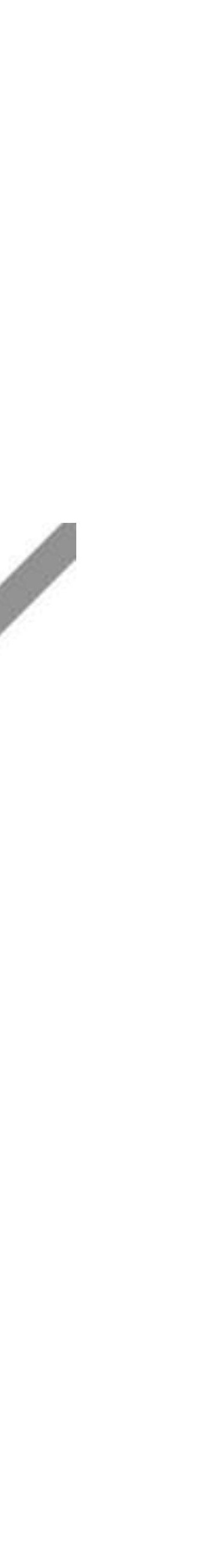


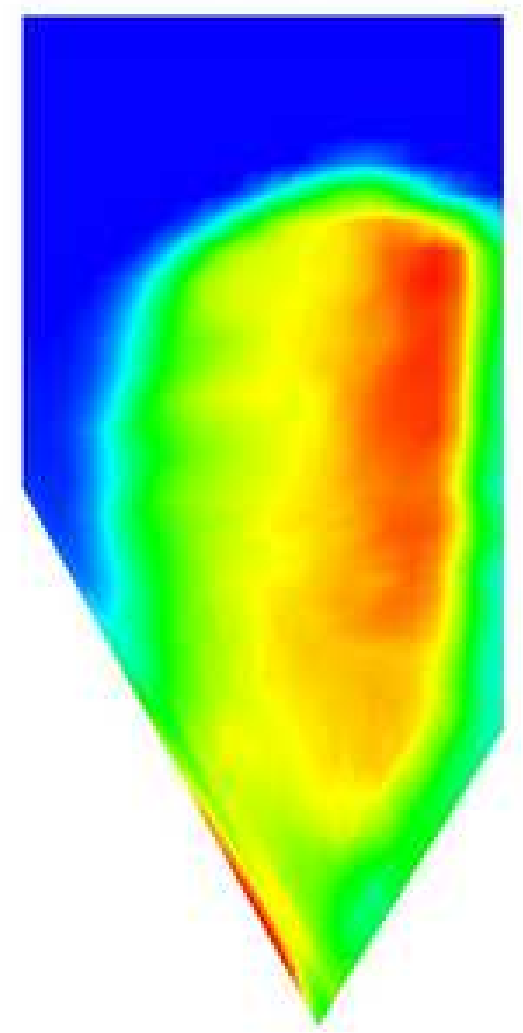

(a) $22.5 \mathrm{~mm}$, Original method

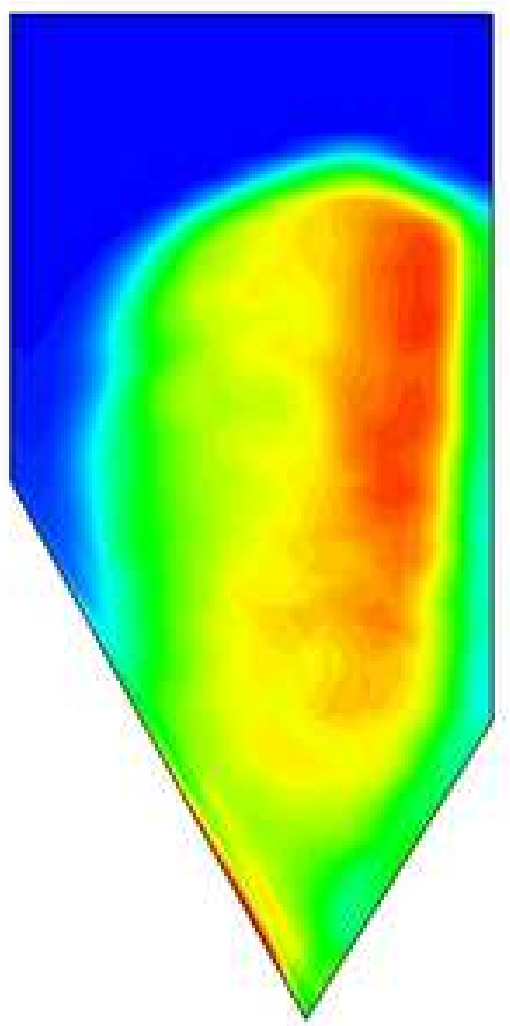

(c) $22.5 \mathrm{~mm}$, New method

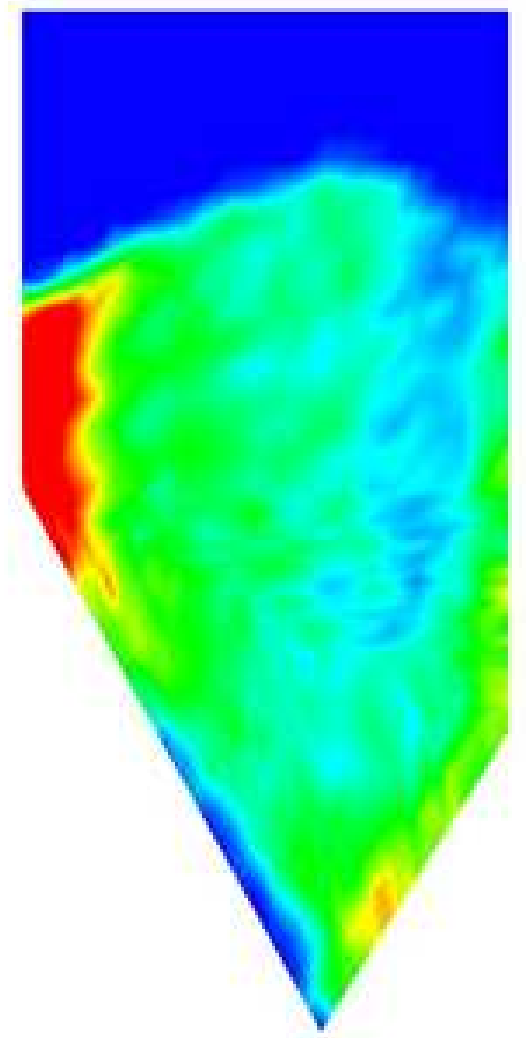

(b) $97.5 \mathrm{~mm}$, Original method

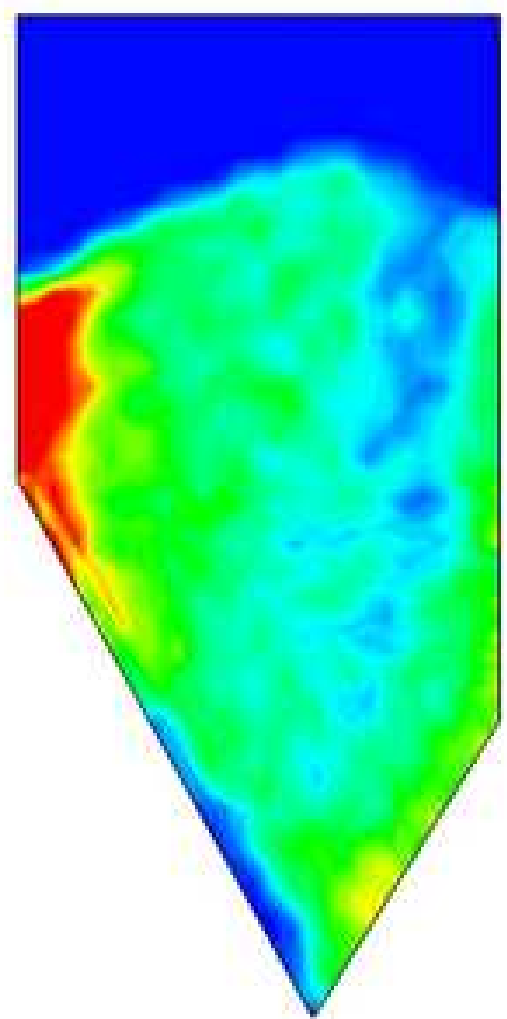

(d) $97.5 \mathrm{~mm}$. New method

$$
\begin{array}{lll}
W / W_{0} & 0 & 1.4 w t^{\circ}
\end{array}
$$




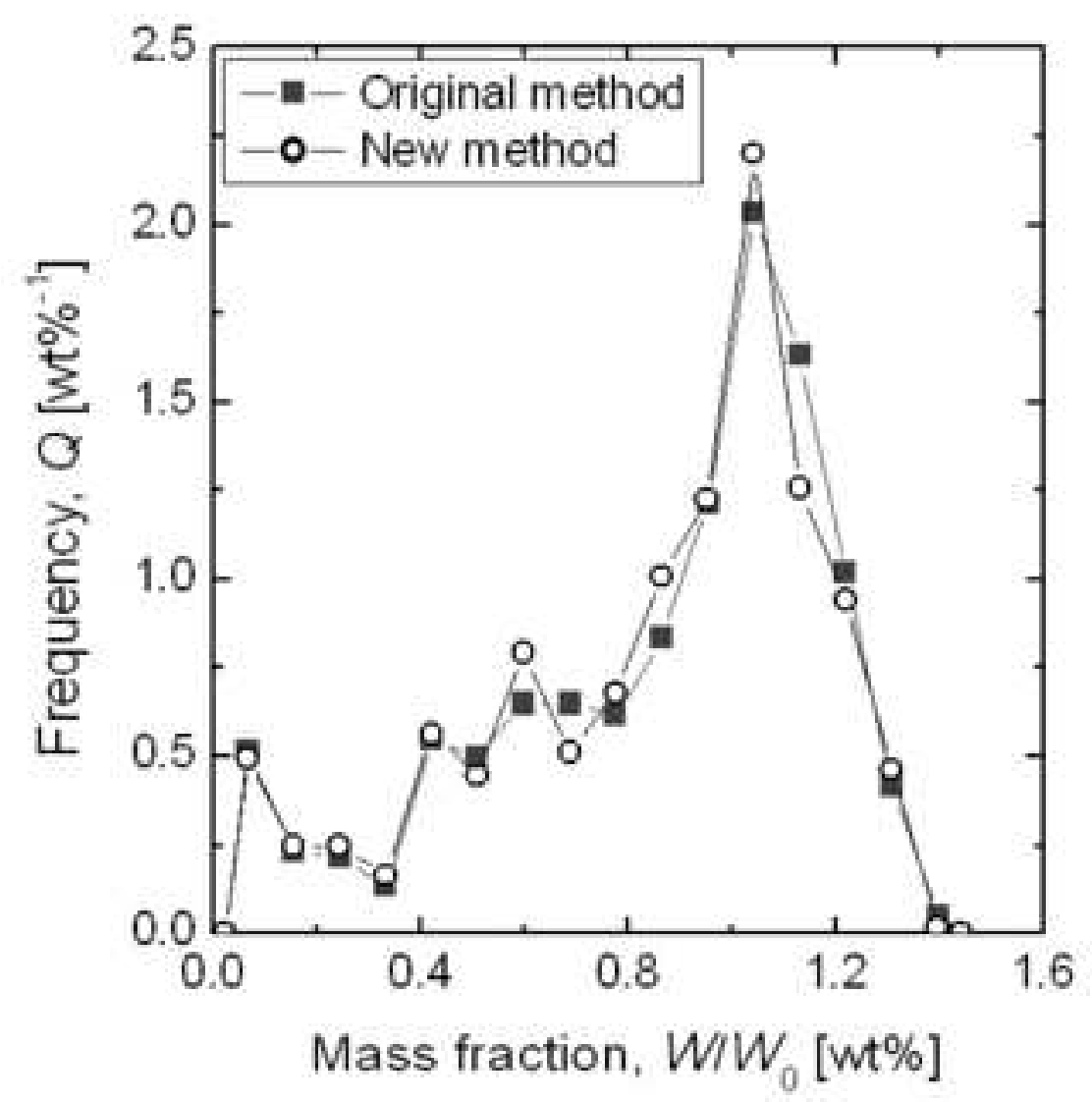

(a) $22.5 \mathrm{~mm}$

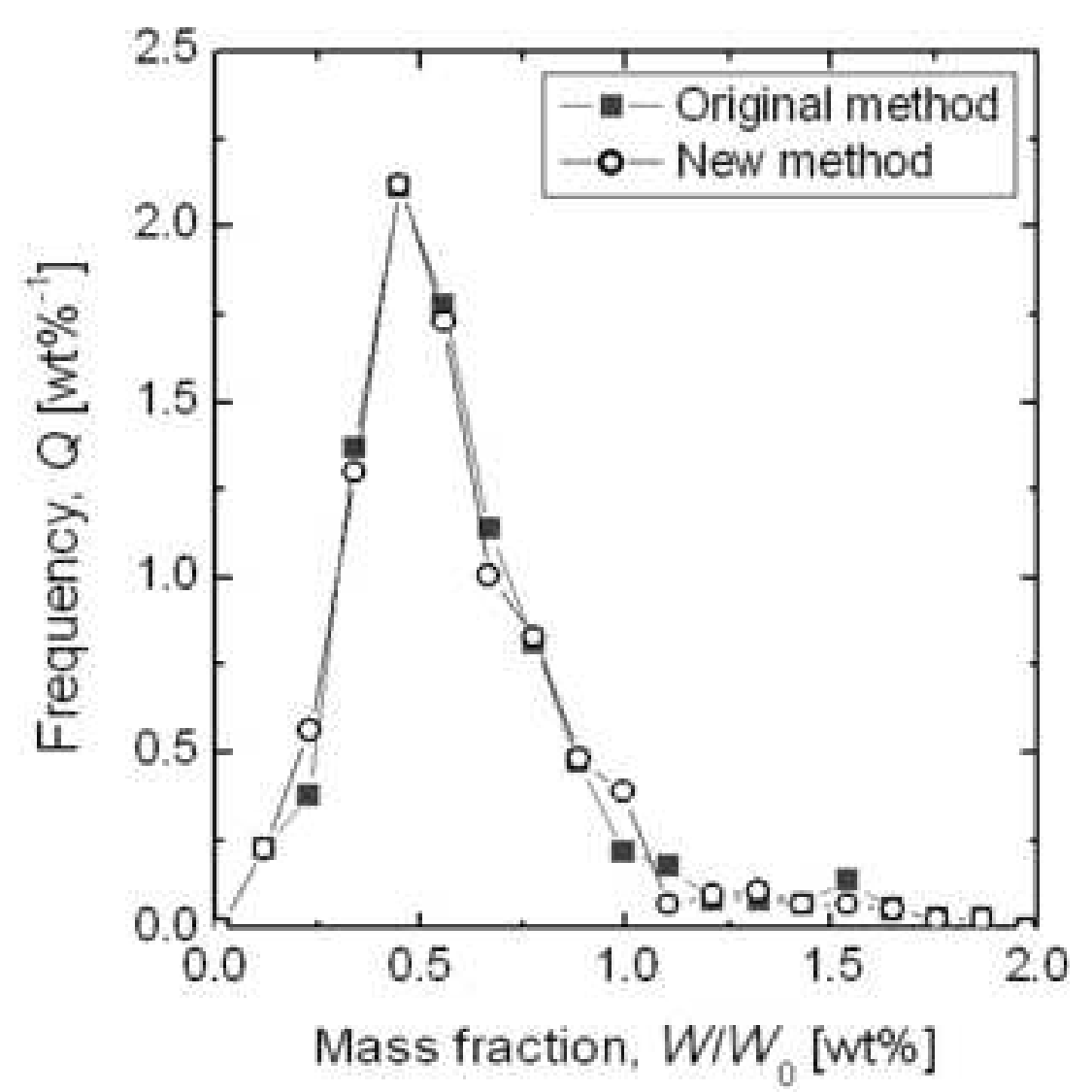

(b) $97.5 \mathrm{~mm}$ 